\title{
CAMBIO AGRARIO Y DESARROLLO INDUSTRIAL NO FABRIL EN LA ISLA DE MALLORCA, 1830-1930 *
}

\section{CARLES MANERA}

Universitat de les Illes Balears

\section{RESUMEN}

El trabajo pretende apuntar las grandes líneas del cambio que se produjo en la economía de Mallorca entre 1830 y 1930, centrándose el análisis en dos ejes claros: la evolución del modelo agrario preindustrial, con el avance de cultivos con demanda creciente en los circuitos comerciales (almendras, vinos, cítricos), $y$, particularmente, el desarrollo de una industria sustentada sobre sectores no líderes y con protagonismos evidentes en actividades como la fabricación de jabones, de tejidos de lana y de calzado. Los cambios que se analizan constituyen, según el autor, una base mucho más sólida y diversificada que la que se presuponia hasta el momento sobre la economía mallorquina.

* En este texto se recogen algunos de los argumentos que presenté en mi Memoria de Doctorado en Ciencias Económicas, Desarrollo económico y acritudes empresariales en la Mallorca contemporánea, 1730-1930. Rasgos económicos esenciales de una sociedad preturística, Facultat de Ciències Econòmiques i Empresarials, Universitat de les Illes Balears (octubre de 1995), 310 pp. (inédita), y que constituye la base de mi Tesis Doctoral en Ciencias Económicas, en curso de elaboración. He ofrecido un avance de estas investigaciones en el Seminario de Historia Económica La desindustrialización a partir de la industrialización, dirigido por Jordi Nadal, Fundación Duques de Soria (1996); en el Seminario de Historia Económica Regional, coordinado por Jordi Maluquer de Motes y Luis Germán, Universitat Autonoma de Barcelona (1997); y en el Congreso de la Asociación de Historia Económica, Girona (1997). Agradezco los comentarios y las sugerencias de mis colegas del Seminario de Historia Económica de la Universitat de les Illes Balears, y las observaciones de Enrique Llopis, Ernest Lluch, James Simpson, Carles Sudrià y de dos evaluadores anónimos. Los errores subyacentes son de mi exclusiva responsabilidad. 


\section{ABSTRACT}

The aim of this study is to establish the broad outlines of the changes in the economy of Majorca between 1830 and 1930. It focusses in two major areas: the evolution of the pre-industrial agricultural model, with the advance of crops meeting a growing demand from commercial networks (almonds, wines, citrus fruits), and, in particular, the development of industry sustained by non-leading sectors, such as the production of soap, woollen cloth and footwear. In the author's opinion the changes analysed show that the Majorcan economy had a much more solid and diversified base than has hitherto been supposed.

\section{INTRODUCCIÓN}

La escasez de investigaciones sobre la evolución de la economía de Mallorca durante los siglos $\mathrm{XX}$ y $\mathrm{xX}$ es patente. Los estudios publicados a lo largo de los años sesenta y setenta sobre el Ochocientos insular constituyen, todavía, los puntos cardinales de referencia para historiadores económicos y economistas, huérfanos de una perspectiva actualizada sobre la progresión reciente de la estructura económica mallorquina ${ }^{1}$. Esto hace que sean insuficientes (y poco satisfactorias) las visiones de conjunto disponibles, construidas, en la mayoría de casos, a partir de tópicos y explicaciones mecánicas. El más común es el de la Mallorca perennemente ruralizada hasta la llegada del turismo de masas, con pocas variaciones en la agricultura y en la industria, presentada esta última como irrelevante. De sociedad agrícola, pobre, monótona y estancada, Mallorca pasaba, junto al resto del archipiélago, a liderar la renta per cápita de las comunidades autónomas y se situaba en una palestra privilegiada entre las regiones europeas. Nadie se pregunta seriamente cómo se produjo el milagro, qué bases lo indujeron, de dónde provenían los capitales que lo impulsaron, qué se dejó en la cuneta al optar por la construcción de hoteles y residencias turísticas, qué costes socioeconómicos y ecológicos ha comportado este modelo desordenado de crecimiento, apodado negativamente como «balearización».

En este sentido, el estudio que se presenta pretende apuntar algunos de los cambios acaecidos en décadas anteriores al fenómeno turístico, transformaciones que sugieren una economía mucho más compleja y rica en situaciones y resultados que las presuncionès de los discursos más publi-

\footnotetext{
${ }^{1}$ Cf. B. Barceló (1964), M. Alenyar, B. Barceló y P. Carlos (1982).
} 
citados. A su vez, se enfatiza la formación de grupos comerciales e industriales que resultaron determinantes para la integración de algunos productos insulares (agrícolas y manufactureros) en los competitivos circuitos de un capitalismo en pleno proceso de consolidación. Esta progresión no puede desvincularse de otras realidades igualmente influyentes, representadas por crecimientos de carácter sectorial como los de la agricultura comercializable (son los casos de almendras, cítricos y vinos) que, a su vez, imbuyeron de forma notable en la creación de sociedades de crédito $y$, por consiguiente, en la génesis de entidades financieras dinámicas desde el último tercio del siglo $\mathrm{xx}^{2}$. El conjunto de todos estos elementos presiente que nos encontramos ante una estructura socioeconómica claramente inserta en los diversos flujos de la economía mundial, en la que la división del trabajo parece adjudicar a Mallorca el papel de avitualladora de alimentos y productos transformados y algunos géneros industriales.

A partir de esta reflexión de carácter general, he organizado la investigación en dos grandes bloques: uno que enfatiza el cambio agrario a partir de indicadores generales sobre producción agrícola y extensión de cultivos, el impacto resultante sobre sectores concretos de la incipiente industria y su contribución conjunta al desarrollo urbano; y otro que reafirma un crecimiento industrial que se apoya sobre pautas organizativas intensivas en trabajo, en las que talleres y pequeños centros productivos dominan sobre la gran fábrica. La estructura económica que se apuntala hasta los años 1930 - si bien urge analizar el período que abraza hasta la década de 1950- es, a mi entender, la que protagoniza el gran salto que significa el turismo de masas.

\section{CAMBIO AGRARIO, AVANCE MANUFACTURERO Y PROCESO URBANIZADOR}

\subsection{Coordenadas generales: el incremento de la producción agrícola, 1830-1860}

Cereales y aceite constituyeron los capítulos fundamentales de la economía productiva insular a lo largo del siglo xviI hasta aproximadamente los años 1840. Sin embargo, ya es bien conocida la presencia de otros

${ }^{2}$ Tal y como apunta L. Alemany (1973), pp. 173-179. También P. Tedde (1974), vol. 1, pp. 408 y ss. 
géneros que disponían de una cuota mercantil y cuya producción también podia obedecer a la estrategia del pequeño campesinado ${ }^{3}$. Este planteamiento comporta, implícitamente, la apuesta por un nuevo modelo agrario que se dibujaría, nebuloso, desde la segunda mitad del siglo XVII, se extendería con mayor o menor intensidad - según las comarcas- durante el XVWI y primeras décadas del Xxx y se impondría, sólidamente, desde los años 1850. Las producciones frumentarias y oleícolas, en las que nobles y comerciantes eran protagonistas esenciales, coexistirían por tanto con algarrobos, almendros, cítricos, hortalizas, leguminosas, viñas y con el avance de la ganadería porcina y la irrupción decidida de las higueras - cuyo fruto se traduce en el alimento primordial de los cerdos - en explotaciones mucho más modestas que las poderosas «possessions», en donde el policultivo era más firme y seguro ${ }^{4}$. La decisión del campesino en asignar recursos hacia esos géneros puede explicarse tanto por condicionantes edafológicos como por la necesidad de entrar en los circuitos del mercado, ya de manera voluntaria, ya forzada. La investigación de carácter microeconómico, todavía poco explorada, es crucial en estos casos, si bien las variables de conjunto sistematizadas, sin duda insuficientes y a veces poco fiables, permiten atisbar la evolución que configura el cambio en la agricultura mallorquina (cuadro 2).

Las cifras presentadas muestran el aumento de la producción agraria entre 1760 y 1860 , crecimiento que es más ostensible a partir de $1835^{5}$. En efecto, desde 1760 y hasta 1835 la producción cerealícola permaneció claramente estancada, mientras la oleícola retrocedía sin paliativos. En tal sentido, los granos conocieron una tímida recuperación en el último tercio del siglo XVIII, mediatizada por la caída de los precios a partir de $1820^{6}$. Éstos declinan en una coyuntura en la que, presuntamente (faltan datos entre 1835 y 1860), aumentaría la producción, si se tienen en cuenta las magnitudes establecidas para 1860. En tal sentido, Ángel García Sanz ha argumentado ${ }^{7}$ que los criterios capitalistas contables no funcionaban en las empresas agrarias dominantes a comienzos del Ochocientos, a la hora

${ }^{3}$ C. Manera (1990), pp. 7.84.

4 Véase desde un plano más general, M. Aymard (1983), pp. 1394-1397.

'El incremento de las cosechas cerealícolas es uno de los elementos que caracterizan la agricultura espaniola en su conjunto en los primeros años del siglo XIX, si bien existen diferencias para consensuar una cronologia más precisa sobre cuándo se inicia ese proceso. Véase A. García Sanz (1985), J. Fontana (1985) y E. Llopis (1985). Una visión más general en J. Fontana (1974), pp. 15-79, y G. Tortella (1994), pp. 19-28.

6 J. Suau (1991), p. 307.

A. García Sanz (1985), pp. 79-80. 
de asignar el factor trabajo en la unidad de producción campesina. La estrategia de producir más para contrarrestar el derrumbe de los precios significaba una respuesta en manos del campesinado, concretada en un trabajo más intensivo, pero no en un mayor gasto; en definitiva, en un sentido claro de autoexplotación que no eludía, sin embargo, formas resistenciales como el impago por ocultación de impuestos en especie y diezmos que se desviaban hacia el mercado ${ }^{8}$. Por otra parte, los mecanismos de ajuste de la economía española en esos momentos provocarán, como es bien sabido ${ }^{9}$, una corriente de protección del mercado interior, lo cual contribuyó a que los esfuerzos se encarrilaran hacia la producción de cereales, asociados a leguminosas y a determinados cultivos arbóreos. Esto es igualmente detectado por los datos expuestos anteriormente: entre 1835 y 1860 , la producción cerealícola aumenta un 47 por 100 y la de legumbres un 73 por 100, mientras que las almendras prácticamente duplican su cosecha, las algarrobas casi la triplican y las higueras multiplican por quince su producto final. El aceite, que en 1860 avanza en relación a 1835 (un 37 por 100), experimenta esa ligera mejoría pero en un marco de decadencia: su declive es nítido desde 1760; otras producciones - aguardiente, almendrón, queso, tejidos bastos de lana y lino- le relevan en aquellos mercados donde antes era requerido de forma hegemónica.

Estas consideraciones se homologan con las magnitudes calculadas sobre superficie cultivada desde 1860 , dilatándose hacia el siglo $\mathrm{Xx}$ las transformaciones agrícolas discernidas a comienzos del Ochocientos:

La lectura conjunta de los cuadros 1 y 2 ofrece escasas dudas: desde la segunda mitad del siglo xx, granos y olivos reducen gradualmente su presencia en el campo mallorquín; mientras que los plantíos de algarrobos, almendros e higueras mantienen una tendencia expansiva evidente y los viñedos apuntalan una coyuntura favorable entre 1820 y 1885 , aunque marcada por fuertes irregularidades. En 1860 , el 20 por 100 de la producción agrícola de la isla provenía de los últimos géneros citados, cuya concurrencia no era tan relevante en épocas anteriores, con la única excepción de las mercancías vitícolas. En 1875, algarrobas, almendrones, frutas diversas (limones, manzanas, naranjas), higos (en relación directa al avance de la ganadería porcina) y vinos componían el 25 por 100 de los valores agrícolas. En 1911 ese porcentaje ya alcanzaba el 42 por 100 y se mantenía

B J. Fontana (1985), pp. 122-126.

${ }^{9}$ P. Pascual y C. Sudrià (1992), pp. 125-142. 


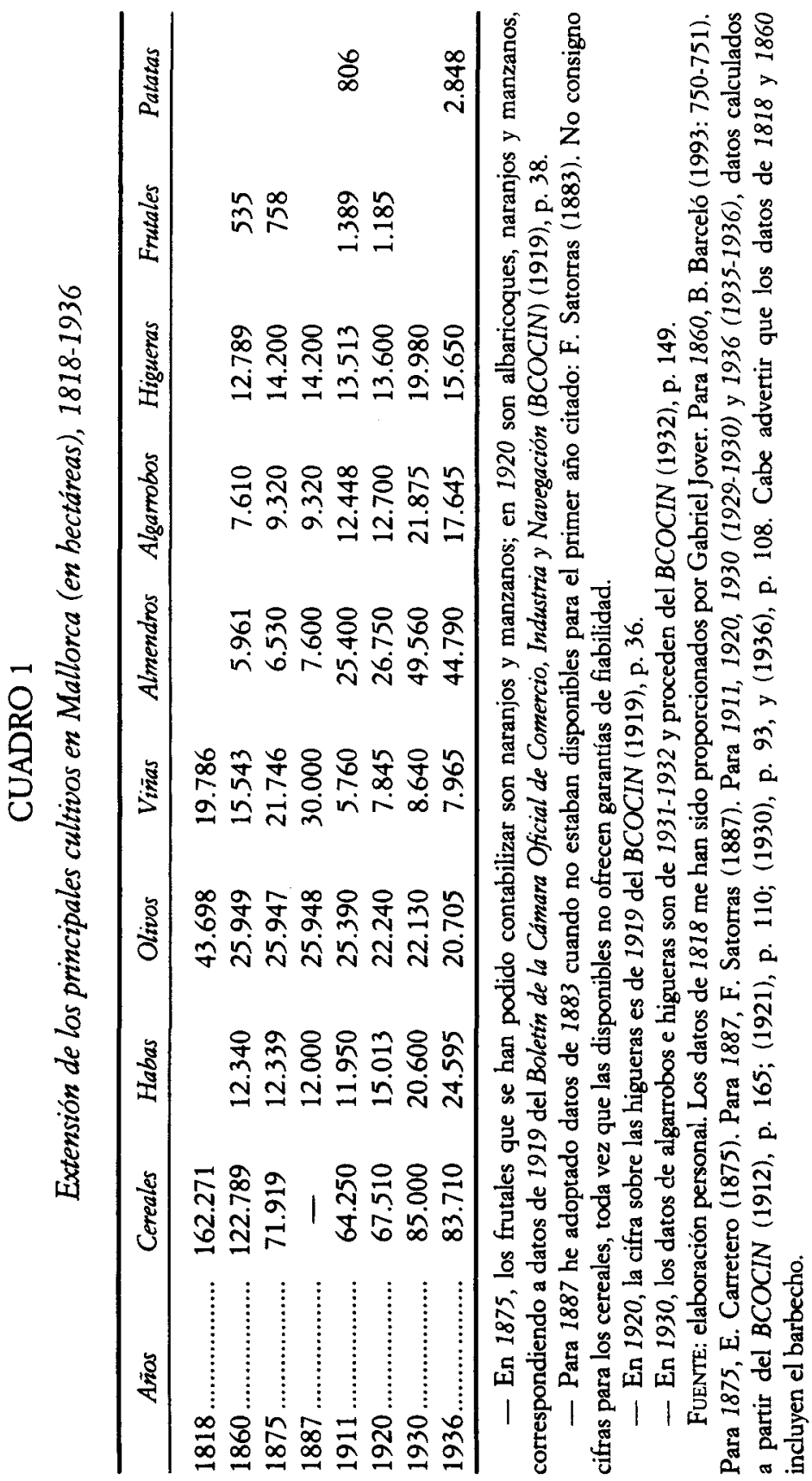




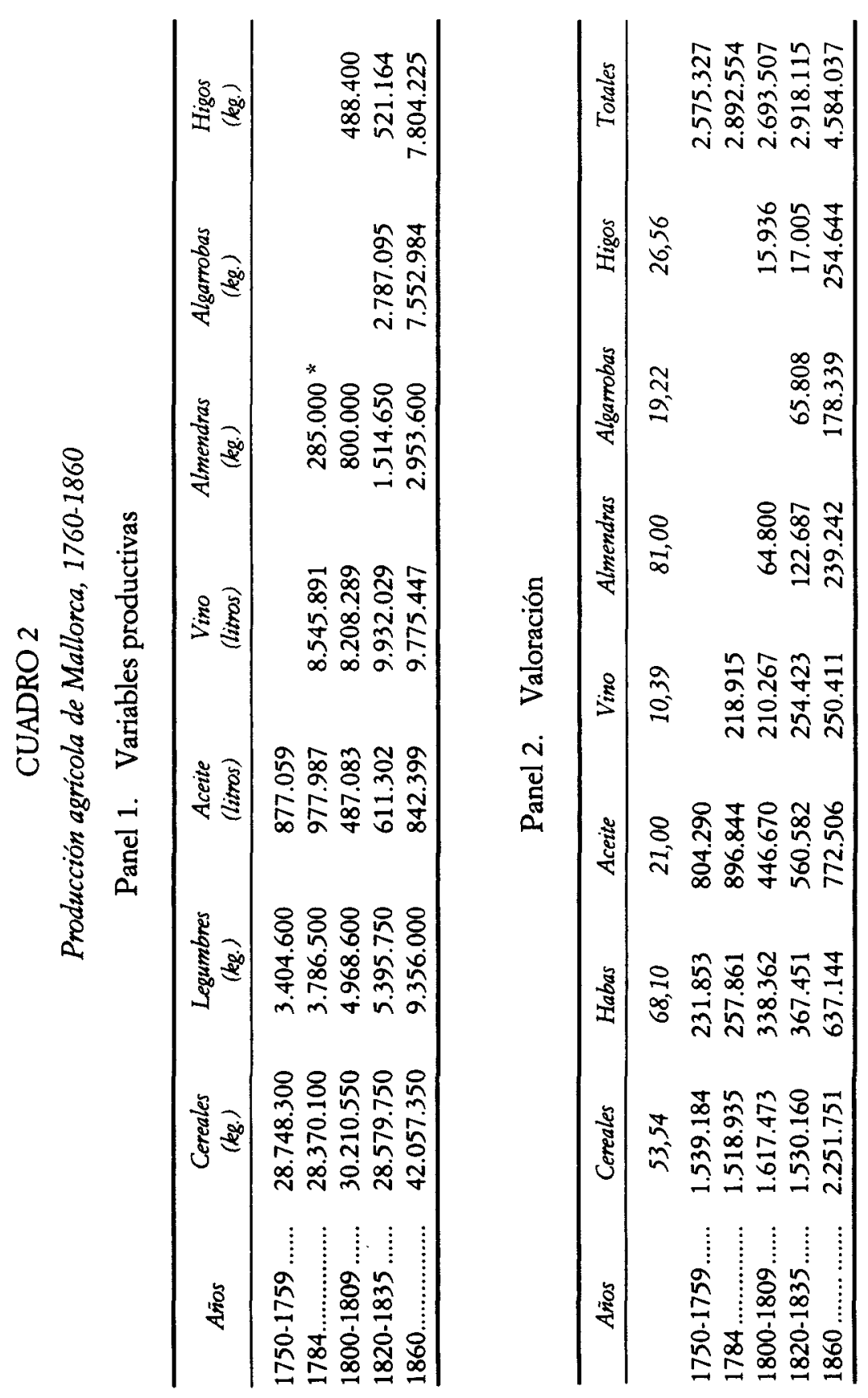




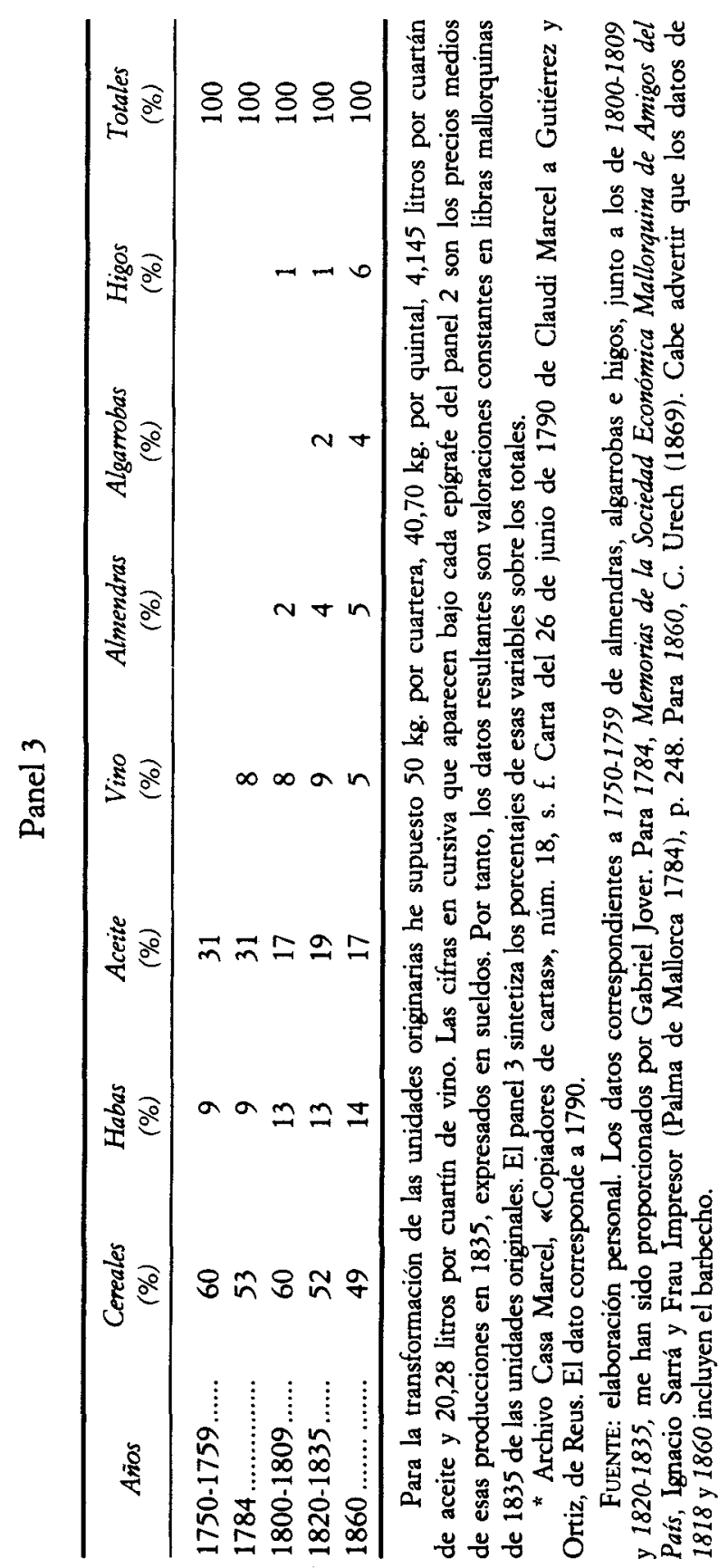


en torno al 40 por 100 en $1922^{10}$. El cambio agrario estaba plenamente consolidado.

\subsection{Agricultura e industria: transformación del modelo agrario y desarrollo industrial}

El 1 de agosto de 1883, el ingeniero agrónomo Francisco Satorras rubricaba en la ciudad de Palma un largo informe sobre el estado de la agricultura balear, donde afirmaba que de medio siglo a esa parte se ba operado un cambio completo en el estado económico de la Agricultura balear. La población ba tenido un gran aumento, el valor de algunas fincas ba triplicado o cuadriplicado, tanto en arriendo como en venta, la cantidad de productos inmensamente mayor, el jornal del hombre ba experimentado un gran aumento y además hoy encuentra el labrador abundante trabajo ${ }^{11}$. La percepción del técnico, un hombre escrupuloso en sus observaciones y diagnósticos (a juzgar por otros documentos disponibles que llevan su firma), se enmarca en un cierto triunfalismo que el propio autor se encargó de matizar convenientemente a lo largo de las páginas que dedica al cambio agrario. Pero una cosa queda clara en las consideraciones que se comentan: para Satorras, el proceso arrancaba de los años 1830 y se extendía, gradualmente, a lo largo de la centuria. La causa central argüida por el ingeniero para explicar ese avance era la fragmentación de la propiedad agraria y los rápidos adelantos que ba becho la arboricultura, extendiéndose por todas partes y dando a las tierras un valor tan superior al que antes tenian. Ahora bien, un segundo elemento se perfila con claridad en las explicaciones del cualificado funcionario:

A Mallorca le ba cabido la bonra de ser uno de los países españoles que en menos tiempo ba adoptado mayor cantidad de instrumentos agricolas per-

${ }^{10}$ Los porcentajes de los valores de 1860 se encuentran en la tabla sobre producción agrícola, en el texto. Los de 1875, 1912 y 1922 son un cálculo personal, aproximativo, a partir de E. Carretero (1875), BCOCIN (1912), p. 165, y A. Ballester (1922). Los textos de Carretero y Ballester (como el de Satorras, citado en la fuente de la tabla sobre extensión de cultivos) se localizan en el Archivo de la Delegación del Ministerio de Agricultura, Palma de Mallorca, sin registro archivístico y sin foliación. Agradezco a Carmen Barceló Ventayol las facilidades para consultar estos fondos recuperados, pertenecientes a los ingenieros agrónomos de Baleares.

${ }^{11}$ F. Satorras (1883), Archivo de la Delegación del Ministerio de Agricultura, Palma de Mallorca. Sin registro archivístico y sin foliación. Esta Memoria continúa otras redactadas en años anteriores (la primera es de 1875). 
feccionados, lo cual prueba el espiritu emprendedor de los laboriosos agricultores mallorquines. Con estos instrumentos se va operando una revolución en las faenas agrícolas ${ }^{12}$.

En 1884, y en una línea explicativa parecida, otro ingeniero, Pere d'Alcàntara Penya, definía al agricultor mallorquín como un verdadero industrial, pues no bay ninguno que no se ocupe de una o muchas de las industrias llamadas agricolas, ya por lo que se refiere a la fabricación de vino, aceites o carbones, ya en la misma conservación del fruto de sus cosecbas ${ }^{13}$. Estas laudatorias palabras recogían la significación de una parcela industrial, la agroalimentaria, que patentizaba un claro desarrollo durante la segunda mitad del siglo XIX. De hecho, el cambio en el modelo agrario empezaba a crear tímidas pero estrechas vinculaciones con la industria, estimulada a su vez por la demanda proveniente del campo. Dos sectores se verían particularmente aguijoneados por las transformaciones en el agro: el metalúrgico y el productor de abonos químicos. La conjunción de ambos contribuye a explicar de manera más apropiada el incremento de la producción agrícola y la confirmación de los cultivos comerciales. Penya no hacía más que reafirmar el mismo fenómeno descrito por Satorras, y que no era desconocido en el último tercio del Ochocientos. En efecto, la introducción de maquinaria agrícola en el campo mallorquín constituye uno de los factores que, de manera invariable, resaltan los ingenieros del momento. $\mathrm{Y}$, en ese contexto, tanto Satorras como Penya remarcaban una característica fundamental: los instrumentos que en principio se importaban se iban adaptando a las necesidades propias, siendo rediseñados por fabricantes autóctonos.

En torno a 1860, y al mismo tiempo que se empezaban a admitir en la isla las aradas inglesas del tipo Howard and Berford, se extendía el interés por la fabricación de instrumentos y herramientas relacionados de manera directa con las actividades agrícolas, desde bombas para extraer agua, hasta prensas para la producción de aceite, pasando por la moltura mecánica de los granos ${ }^{14}$. El empresario Joan Oliver Maneu ya fabricaba arados de hierro durante esos años, en una versión modificada de los norteamericanos Wallen. También son anteriores a 1870 los construidos en la fundición Can Sali, de uso frecuente en los predios próximos a Palma. En 1872 llegaba a Mallorca la primera máquina móvil de vapor, aplicada

\footnotetext{
12 F. Satorras (1883).

13 P. d'Alcàntara Penya (1884).

14 Cf. J. Roca (1992), pp. 109-118.
} 
al campo insular: un ingenio para moler de la marca inglesa Ramsome and Sims, consorcio que también instaló algún vapor en el sector textil ${ }^{15}$. Satorras indica que esta trilladora proporcionaba buenos resultados, basta el extremo que hay una sociedad que explota una de ellas trasladándola a diferentes puntos para que la usen los pequeños propietarios mediante un precio módico muy inferior a los gastos que ocasiona la trilla por el sistema antiguo ${ }^{16}$. Pero las máquinas que tuvieron mayor aceptación fueron las segadoras mecánicas, ingenios que se construyen en el pais [y] no son más que modificaciones de las nombradas, siendo las más empleadas unas de madera con los engranajes y ruedas de hierro, modificación de la de Wood, adaptadas a las condiciones del cultivo de arbolado con la reforma en los brazos para que rocen en las ramas de los árboles y queden las gavillas a un lado en vez de caer detrás ${ }^{17}$.

A la vista de estas pruebas, se revela una conclusión evidente: los empresarios no descuidaban las potencialidades de demanda de un mundo agrario necesitado de respuestas precisas e inmediatas por parte de otros sectores de la economía. Estas experiencias, capitaneadas por firmas de dimensiones nada despreciables, se complementaban con el trabajo mucho más rudimentario, poco espectacular, pero igualmente eficiente de una red de herrerías, en general de reducidas dimensiones, que ideaban y fabricaban gran número de utensilios adaptados especialmente a las necesidades de la agricultura local. Así pues, segadoras, sembradoras, trilladoras, descascarilladoras de almendras e incluso, ya a principios del siglo $\mathrm{xx}$, un tipo particular de turbina utilizada para prensar la vendimia ${ }^{18}$, constituían los productos más significativos que nacían de pequeños talleres, cubriendo así algunas de las demandas agrícolas.

${ }^{15}$ En concreto, en 1872 en la fábrica de tejidos de algodón del industrial Vicente Juan; J. Roca (1992), p. 110, nota 4; y en 1874 en la empresa de tejidos de lana de Sebastià Barcelo; A. Penya (1990), p. 56, nota 9.

${ }^{16}$ F. Satorras (1883).

17 F. Satorras (1883).

${ }_{18}$ Este ingenio se patentó en 1922 bajo el nombre de Unix Cilindro. La industria vitícola creará nexos importantes con otros sectores, como el de la madera. Felanitx, por ejemplo, contaba en 1877 con dos fábricas de construcción de botas de roble, capaces de producir depósitos que anualmente sumaban 550.000 litros. Otras empresas disponían de talleres propios, como la denominada La Perfección, creada en 1882 en Manacor y consagrada a la elaboración a gran escala de anisados y licores. La construcción y reparación de alambiques constituyó también una actividad desarrollada en aquellas villas vinícolas. Así, Felanitx tiene una fabricación de aparatos destilatorios de cobre en la que se construyen desde el modemo alambique ordinario basta el complicado tipo Derosnes. Véase Anuario de la Bolsa, del Comercio y de la Banca, Tipografía de R. Álvarez (Madrid, 1896), y Estudio de la Exposición Vinícola Nacional (Madrid, 1877); J. Roca (1992), p. 111, nota 8. 
En relación a los abonos químicos, es posible que la utilización de fertilizantes minerales en Mallorca fuera ya frecuente hacia 1900. En 1883, Satorras explicaba que algunos propietarios empiezan a usar los abonos quimicos aunque en pequeña escala, mejora que es de esperar se generalice con el tiempo ${ }^{19}$. Estiércol, residuos vegetales y guano constituían los principales elementos nutrientes de la tierra aplicados por el hombre. Pero la aparición de numerosas publicaciones divulgativas y propagandísticas sobre abonos inorgánicos, editadas en la isla ${ }^{20}$, pretendían, con toda seguridad, convencer al agricultor de las ventajas en la utilización de estas nuevas entradas en el proceso de producción. Algunos empresarios se arriesgaron a elaborar lo que se debería adquirir en el exterior. En 1908 existía en Palma una modesta razón social, Ripoll Hermanos, dedicada a la fabricación de abonos químicos. En 1911 ampliaba su negocio, tanto las instalaciones como su equipamiento técnico, enriquecido ahora con 24 hornos para quemar piritas de hierro (procedentes de Cartagena y Huelva) y dos cámaras con capacidad de 2.500 metros cúbicos para la obtención de ácido sulfúrico, el componente fundamental para los superfosfatos. La energía de la fábrica dependía de un motor de gas pobre de treinta caballos de potencia y de una máquina de vapor de quince caballos. Esa inversión generó unos resultados productivos nada despreciables en el mismo 1911, teniendo en cuenta que se trata de una empresa de medianas dimensiones: 6.000 toneladas de superfosfatos de calcio, 188 toneladas de sulfato de amoniaco y 50 toneladas de sulfato de hierro. Las cifras son significativas si se tiene en cuenta que todo se consumía íntegramente en Mallorca ${ }^{21}$. En 1913, esta sociedad comanditaria se convirtió en anónima, con el nombre de La Fertilizadora. La empresa había llegado a un alto nivel de organización y de diversificación productiva, tal y como se desprende en su declaración de principios ${ }^{22}$. En pocos años, trasladará sus locales a los nuevos muelles del puerto de Palma (Porto $\mathrm{Pi}$ ) en donde contará con puntos de atraque propios para facilitar la extracción de los excedentes que la demanda insular no puede

19 F. Satorras (1883).

${ }^{20}$ Desde 1875 se tienen noticias de distintos experimentos con abonos minerales en Mallorca, promovidos por agrónomos y aplicados con poco éxito al cultivo del trigo y de la viña. Los resultados más favorables fueron los alcanzados en la villa de Campanet en 1898, a partir de la utilización de nitrato de sosa. Obras de la época sobre el tema son: P. Estelrich (1900) y F. Satorras (1901). La aplicación de abonos químicos fue un tema de debate en el XV Congreso de la Federación Agrícola Catalano-Balear, celebrado en Eivissa en 1912; J. Roca (1992), p. 113, nota 22.

${ }^{21}$ La Región, Palma de Mallorca, 5 de febrero de 1912.

${ }^{22}$ La Fertilizadora, Abonos minerales. Instrucciones para su aplicación en Mallorca, Imprenta A. Homar (Pont d'Inca, 1913). 
consumir. En 1930, la empresa se ha convertido en una de las más importantes de España en su sector. Los datos son meridianos: ocupa a unos 200 trabajadores y produce unas 50.000 toneladas de superfosfatos, 12.000 de ácido sulfúrico y 3.000 de sulfato de hierro y de ácido nítrico. En 1934 amplía su radio de influencia construyendo una segunda fábrica en las afueras de la capital (Son Forteza), cerca de la línea del ferrocarril, a la que se encuentra unida gracias a una vía de uso particular ${ }^{23}$.

Las muestras presentadas, referidas a dos de los sectores más modernizados de la industria mallorquina, sancionan la importancia de las conexiones entre ésta y la agricultura, vínculos que engloban igualmente a las actividades manufactureras tradicionales -con la creación de economías externas en ambos casos- y a la fuerza de trabajo que interviene en los procesos productivos. No es posible entender correctamente la evolución industrial de Mallorca sin tener en cuenta ese importante proceso de cambio en el mundo agrario a partir de los años 1830.

\subsection{Dinamismo económico y urbanización}

Las relaciones recíprocas entre el mundo agrícola y el industrial comportaron en Mallorca el avance de la urbanización, un fenómeno que se hace perceptible sobre todo a partir de 1830. Desde una óptica general, es sabido que la industrialización contemporánea significó un desarrollo notable de las ciudades. Algunas zonas rurales, con industrias vigorosas, empezaron a languidecer a causa de la movilidad demográfica; no obstante, otras siguieron aferradas a sus oficios manufactureros, disponiendo asimismo de un protagonismo económico, tecnológico, cultural y social innegable. Por otra parte, las ciudades cubrieron otras funciones que las meramente industriales, tal y como nos ha enseñado E. Anthony Wrigley ${ }^{24}$. Jan de Vries ha indicado que el ascenso de ciudades de dimensiones más

${ }^{23}$ Anteproyecto de Plan Económico (1947-1951). Junta Provincial de Ordenación económico-social de Baleares, Imprenta Mossén Alcover (Palma de Mallorca, 1951).

${ }^{24}$ A. García y M. Guàrdia (1987), pp. 143-170, con interesante aparato bibliográfico. Por el contrario, J. Rule opina que, entre 1750 y 1850, Londres debe ser considerado como un gran centro industrial: cf. J. Rule (1990), p. 36. Consúltese igualmente E. A. Wrigley (1992), pp. 189-270, sobre todo pp. 191-200. Para Wrigley, los cambios en la ciudad obedecen a un proceso de modernización que representa un paso previo e ineludible para la Revolución industrial. Los ejes de esa modernización - término que es, sin duda, ambiguo- son para dicho autor el incremento de la renta real per cápita, el aumento de la productividad agraria, el cambio de régimen demográfico y, como colofón, el crecimiento urbano. 
reducidas que los grandes centros urbanos pudo producirse por algún otro estímulo diferente a la atracción ejercida por el sistema fabril. De Vries lanza una hipótesis al respecto: ese acicate tal vez se encontrase en el aumento de los ingresos y de la producción en el sector agrario ${ }^{25}$. La coincidencia en estos puntos con Wrigley es clara: para este último, los niveles de productividad per cápita de la agricultura gobiernan sin discusión las posibilidades de desarrollo de otras actividades ${ }^{26}$. Sin embargo, es un ejercicio complicado medir esa productividad agrícola, si bien una forma de determinarla, por procedimientos indirectos, sea considerar la evolución del crecimiento urbano teniendo presentes las transformaciones en la estructura ocupacional de la población rural ${ }^{27}$.

Para Mallorca, desde fines del siglo xvw y, sobre todo, a partir de 1830, se va acentuando de manera paulatina el peso de la ciudad de Palma como núcleo de consumo, de producción y desde el que se vertebra una parte importante de la infraestructura distributiva que ayuda a articular el mercado interior insular. El aumento demográfico inducirá el traslado a la urbe de jornaleros y artesanos con el objetivo de trabajar en la manufactura, hecho que impulsó un crecimiento urbano imposible de concretarse, años más tarde, en el marco estricto de las murallas. La estructura agraria conocerá, entonces, cambios importantes motivados por esas corrientes de migración rural. La pequeña propiedad se extenderá en los arrabales de la ciudad, siendo las parcelas más frecuentes las mixtas agrícola-residenciales, definidas por una economía familiar que combinaba el cultivo de un pequeño trozo de tierra con un trabajo agrícola $\mathrm{y}$, generalmente, artesano; o con actividades propias de un domestic system, encuadradas en el sector textil ${ }^{28}$. Por consiguiente, Palma concentraba segmentos significativos de la manufactura, si bien algunos pueblos de la zona rural se iban especializando en capítulos concretos ${ }^{29}$. En efecto, la importancia demográfica de Palma no debería marginar una percepción mucho más general del conjunto insular. La urbanización no sólo afectó al principal

25 J. de Vries (1987), pp. 332-333.

${ }^{26}$ Cf. igualmente M. Berg (1987), p. 107.

27 E. A. Wrigley (1992), pp. 234-235.

${ }^{28}$ Ver M. A. Carbonero (1987), pp. 49-66, y (1991), pp. 91-107. Consúltese también V. M. Rosselló Verger (1982), pp. 45-52. Rosselló señala el paralelismo existente entre la formación de esas parcelaciones y los inicios de la industria del calzado en Llucmajor a principios del siglo xx.

${ }^{29}$ Cf. los trabajos de J. M. Escartín, A. R. Serrano y A. Vidal sobre Esporles (lana), Sóller (algodón) y Llucmajor (calzado), respectivamente, en C. Manera y J. M. Petrus (1991), pp. 107-149. 
enclave mallorquín, sino que se hizo sentir con cierta intensidad en otras áreas. Los datos que se tabulan en el cuadro 3 aportan pistas esenciales. Debe advertirse que las variables que se exponen han de adoptarse con suma prudencia, desde el momento en que resulta arbitrario trazar el límite entre lo urbano y lo no urbano en una comunidad de 5.000 personas ${ }^{30}$. Sin embargo, lo que están sugiriendo en el largo plazo es el perfil de una tendencia desde un doble plano: la estabilidad relativa de la ciudad de Palma (en torno al 25 por 100 del total demográfico) y el peso global, cada vez más importante, de aquellos núcleos superiores a 5.000 habitantes.

En relación a la primera urbe, su gran salto demográfico se produce entre 1825 y 1860 , al ver incrementados sus habitantes en más de 17.000 individuos. Sin embargo, el proceso más interesante se aprecia en el intervalo que oscila entre 5.000 y 15.000 personas: el crecimiento es aquí imparable, tanto en términos absolutos como en valores porcentuales, y progresivamente engloba a un número cada vez mayor de villas; al mismo tiempo, cae sin discusión el contingente demográfico que habita en los vecindarios más pequeños-que de 35 censados en 1750 pasan a 19 en 1860 - no superiores a los 2.000 moradores. La cuestión mantiene una relación directa con cambios en estructuras económicas locales. El presumible aumento de los niveles de «urbanización» se contempla en aquellas comarcas que, desde la segunda mitad del siglo xvir, empiezan a conocer variaciones significativas en su economía, con franjas del campesinado especializadas en cultivos comerciales, ingresos más elevados en comparación con otras zonas de la isla y comportamientos demográficos igualmente diferenciados ${ }^{31}$. Este pequeño pero consistente grupo pasa de representar poco más del 9 por 100 del total de la población mallorquina a mediados del xvш, hasta llegar al 30 por 100 en 1860. El dinamismo de unas economías en las que los resortes feudales eran menores, más diversificadas, orientadas al mercado y con estructuras agrarias en las que la articulación de la pequeña propiedad fue importante, permite entender tal situación. En efecto, con la lógica excepción de Palma, las poblaciones demográficamente más destacadas se caracterizan por sendos factores comunes: su mayor conexión hacia el exterior, y por la presencia de una manufactura que no representaba un sector marginal en sus respectivas economías, proyectando así una tra-

${ }^{30}$ Sobre esto, E. A. Wrigley (1992), pp. 222-223.
${ }^{31}$ Cf. A. Segura y J. Suau (1981), pp. 393-437. 


\section{CUADRO 3}

Estimaciones de la población de Mallorca, de Palma y de poblaciones superiores a 5.000 babitantes

\begin{tabular}{|c|c|c|c|c|c|c|}
\hline & 1591 & 1750 & 1784 & 1797 & 1825 & 1860 \\
\hline Mallorca & 73.643 & 119.620 & 133.900 & 136.671 & 168.110 & 209.064 \\
\hline Palma & 23.161 & 33.121 & 30.263 & 31.942 & 36.617 & 53.019 \\
\hline \multicolumn{7}{|l|}{ Población en villas de más de } \\
\hline 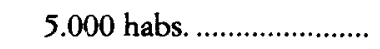 & & 11.285 & 27.452 & 37.805 & 49.088 & 65.072 \\
\hline Total población $>5.000$ habs. & 23.161 & 44.406 & 57.715 & 69.747 & 85.705 & 118.091 \\
\hline \multicolumn{7}{|l|}{$\begin{array}{l}\text { Población «urbana» como } \\
\text { porcentaje del total: }\end{array}$} \\
\hline (n................ & 31,45 & 27,69 & 22,60 & 23,37 & 21,78 & 25,39 \\
\hline Otras villas.............................. & & 9,43 & 20,50 & 27,66 & 29,19 & 31,13 \\
\hline \multirow[t]{2}{*}{ 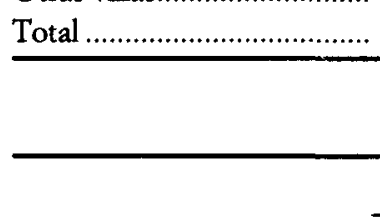 } & 31,45 & 37,12 & 43,10 & 51,03 & 50,97 & 56,52 \\
\hline & 1877 & 1887 & 1900 & 1910 & 1920 & 1930 \\
\hline 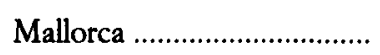 & 230.396 & 249.008 & 248.259 & 257.115 & 269.763 & 292.447 \\
\hline Palma & 58.224 & 60.514 & 63.937 & 67.544 & 77.418 & 88.262 \\
\hline \multicolumn{7}{|c|}{ Población en villas de más de } \\
\hline 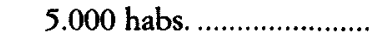 & 80.765 & 105.322 & 92.627 & 90.086 & 103.724 & 108.527 \\
\hline Total población $>5.000$ habs. & 138.989 & 165.836 & 156.564 & 157.630 & 181.142 & 196.789 \\
\hline \multicolumn{7}{|l|}{$\begin{array}{l}\text { Población «urbana» como } \\
\text { porcentaje del total: }\end{array}$} \\
\hline Palma & 25,27 & 24,30 & 25,75 & 26,27 & 28,70 & 30,18 \\
\hline 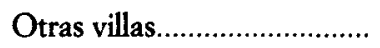 & 35,05 & 42,30 & 37,31 & 35,04 & 38,45 & 37,11 \\
\hline 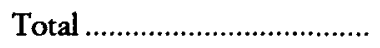 & 60,32 & 66,60 & 63,06 & 61,31 & 67,15 & 67,29 \\
\hline
\end{tabular}

FuENTE: Elaborado a partir de B. Barceló (1962), p. 253.

dición histórica. Los casos de Felanitx y Sóller son los más conocidos ${ }^{32}$. Pero las informaciones hasta el momento codificadas - todavía parcas en algunos, pero así y todo suficientemente ilustrativas-, relativas a Andratx (jabón) ${ }^{33}$, Inca (textil y calzado) ${ }^{34}$ y Llucmajor (molturación de harinas

\footnotetext{
${ }^{32}$ C. Manera (1995), pp. 94-138.

33 A. Pujol (1995).

${ }^{34}$ G. Pieras (1994), pp. 117-126.
} 
y calzado) ${ }^{35}$ determinan la relevancia de un sector secundario que podia estar actuando como reclamo para algunos campesinos, a la vez que probablemente se consolidaba un cuerpo artesanal que funcionaba dependientemente de los encargos fijados por empresarios palmesanos; o bien de manera más autónoma, canalizando sus producciones hacia el mercado interior. Este ascenso de pequeñas ciudades es similar a lo acontecido en otras zonas europeas, siguiendo las pautas de la «nueva urbanización» propuesta por Jan de Vries ${ }^{36}$.

El cambio fundamental parece producirse a partir de la década de 1830. La coyuntura es especial: la producción agraria en su conjunto se expande de manera importante, tras una grave recesión productiva, mientras se contrae la superficie cultivada de cereales y olivar, retrocede ligeramente la de viña y aumenta la dedicada a la arboricultura; la población crece en más de 30.000 personas en términos absolutos, y concentra más de la mitad de sus efectivos (56,52 por 100 en 1860) en ciudades con más de 5.000 habitantes. Esta «urbanización» rural reorienta los resultados conocidos hasta 1784: en 1797, el sumatorio de seis villas (Artà, Felanitx, Llucmajor, Manacor, Muro y Sóller) ya supera el número de vecinos de la ciudad de Palma. Todos estos factores anotan una cuestión que planteo como hipótesis de trabajo, dada la falta de investigación que permita extraer conclusiones fidedignas: bien pudiera ser que el cambio económico que conocen algunas de esas zonas estuviera provocando, esencialmente desde los años 1820-1830, un incremento de la renta real y avances en los rendimientos por hectárea, tanto en los cultivos tradicionales (cereales y legumbres) como, sobre todo, en aquellos que infieren un progreso más firme (algarrobos, almendros, higueras). Ahora bien, los datos disponibles sobre población activa - que deben ser tomados igualmente con gran precaución (véase cuadro 4) - no aseveran transformaciones significativas en la composición sectorial de la economía.

Nada permite augurar que se estuviera generando siquiera una tímida expulsión de trabajadores del campo. Según las cifras anteriores, el peso del sector primario seguía siendo acaparador hasta 1930, si bien el secundario mantenía una cierta regularidad en su composición (con la excepción de 1860 , que recoge guarismos excesivamente bajos). Pero las cifras censales no compilan el estado real de la pluriactividad de la fuerza de trabajo

3s A. Vidal (1992), pp. 83-94.

${ }^{36} \mathrm{~J}$. de Vries (1987), pp. 332-333. De Vries indica que en la región mediterránea el crecimiento de estas ciudades fue más pronunciado en el periodo $1800-1850$, dato en el que Mallorca encaja plenamente. 
CUADRO 4

Población activa en Baleares

\begin{tabular}{cccc}
\hline Años & $I$ & II & III \\
\hline $1797 \ldots \ldots \ldots \ldots \ldots \ldots \ldots .$. & 58 & 17 & 25 \\
$1860 \ldots \ldots \ldots \ldots \ldots \ldots \ldots .$. & 68 & 13 & 19 \\
$1877 \ldots \ldots \ldots \ldots \ldots \ldots \ldots .$. & 66 & 23 & 11 \\
$1900 \ldots \ldots \ldots \ldots \ldots \ldots \ldots .$. & 66 & 22 & 12 \\
$1930 \ldots \ldots \ldots \ldots \ldots \ldots \ldots$. & 37 & 39 & 23 \\
\hline
\end{tabular}

FUENTE: Para 1797 y 1860, M. Martín (1989).

Para 1877, 1900 y 1930, F. Mikelarena (1993), p. 237.

insular. $\mathrm{Y}$ aquí el terreno es muy resbaladizo. Porque muchos artesanos poseían pequeñas parcelas de tierra - los primeros análisis de catastros, apeos e inventarios post-mortem permiten aseverarlo-, de manera que su producción era crucial para la economía doméstica. En muchas ocasiones, las necesidades de las cosechas imponían el reclamo de mano de obra a la población que no dependía de manera directa e inmediata de la agricultura. Y, paralelamente, los que disponían de un trabajo agrícola se dedicaban a actividades no agrarias durante períodos de ralentización en las tareas del campo. La inclusión en un apartado (agricultura) u otro (manufactura) del censo de población dependía de esos condicionantes, que a veces podían representar distorsiones parciales de la realidad en función del momento en que se cumplimentaba el formulario y el trabajo que estaba desarrollando el encuestado. Un dato parece probado, aunque se nos antoje conocido: hombres y mujeres sólo abandonaron parcialmente la agricultura, combinando sus actividades con las propiamente artesanales ${ }^{37}$. Estas consideraciones son de gran importancia para el caso mallorquín, que conoce un proceso nada desdeñable de transformación durante

${ }^{37}$ Véase M. Berg (1987), pp. 110 y ss. E. L. Jones (1974), pp. 314-317. Las contribuciones más recientes sobre el tema, con reconsideraciones generales y síntesis cuidadas, pertenecen a W. Mager (1993) y P. Kriedte, H. Medick y J. Schlumbohm (1993), pp. 181-252. Tanto Mager como Kriedte, Medick y Schlumbohm examinan el tipo de evolución de las industrias nacidas en época moderna en las regiones de industrialización precoz, en sus formas diversas (sistema domiciliario, talleres artesanales o procesos más concentrados) y en sus diferentes contextos (el marco rural y el urbano). El tema más resaltado es, precisamente, la interpenetración de las actividades agrícolas y de la industria a domicilio. También E. A. Wrigley (1992), pp. 235-236. 
la primera mitad del siglo XIX, en unas coordenadas de avance en la producción agrícola, apuntando al mismo tiempo hacia la organización del trabajo manufacturero tanto en pequeñas unidades de producción, como en los albores de la formación de la fábrica auxiliada por el vapor.

\section{UNA INDUSTRIA ARTESANAL DE BASE ORGÁNICA}

\subsection{Características generales}

Entre 1800 y 1930 - aunque en diferentes momentos-, los capítulos de la alimentación, el textil, el metal, el químico (fabricación de jabones) y cuero y calzado vertebraron el secundario insular. Las características más generales de todos ellos pueden sintetizarse así. Por un lado, se trata de sectores que poco tienen que ver con los pautadores de la primera y segunda revolución industrial, de manera que acoplaron la producción a pequeña escala - sin excluir la presencia de la gran fábrica-, adaptaron rudimentariamente la tecnología exterior e insertaron en los procesos de producción a artesanos y campesinos, a hombres, mujeres y niños. Por otro, estamos ante actividades que proyectan experiencias históricas, en absoluto nuevas y que descansan sobre una escasa mecanización y una intensificación del factor trabajo. En este sentido, la tradición mantiene un peso que no es desdeñable, tanto en el textil, como en el cuero o el metal, por citar los casos que son más conocidos. Es por ello que los sectores industriales de Mallorca distinguen - como los de otros lugares-dos niveles de aproximación ineludibles:

1. El tradicional, mayoritario hasta los años 1910-1920, encuadrado más bien en la nomenclatura de Artes y Oficios agrupando al grueso de los operarios de la manufactura, en el que el empresario contaba con la versatilidad del trabajador insular: el mismo jornalero que se encuentra inmerso estacionalmente en tareas agrícolas, puede hallarse pocas semanas o meses después encerrado entre las paredes de una fábrica -0 también en su propio domicilio - faenando con un telar o con las herramientas propias del zapatero. Por consiguiente, los trabajadores industriales de «jornada completa» son la excepción en este panorama. Debe decirse que esto provoca un enorme desconocimiento sobre la situación real de los sectores afectados por este tipo de organización laboral, desde el momento en que la ocultación se convertirá en la principal estrategia impulsada por los industriales. A ello debe añadirse otro aspecto: el papel fundamental 
de las mujeres en determinadas actividades en las que domina de forma clara el sistema doméstico, trabajo femenino generalmente silenciado en las estadísticas oficiales. Casos elocuentes al respecto, referentes a comienzos del siglo Xx (en torno a 1900-1910), son los bordados (con demandas estables en Europa y Sudamérica), la confección de bolsos de plata (solicitados en Alemania, Bélgica, Francia, Inglaterra y en el continente americano) o el calzado (cuyos mercados prioritarios eran Alemania, Cuba, España, Francia y Marruecos) ${ }^{38}$. Este importante segmento manufacturero constata un condicionante energético extensible al conjunto de la estructura económica insular: su escasa mecanización y «vaporización» hace que no se utilicen, o que se haga poco, los vectores clásicos de la revolución industrial. Esta economía se caracterizaba porque el grueso de la energía utilizado en la mayor parte de los procesos productivos procedia, precisamente, de fuentes orgánicas. Es decir, las fuerzas humana y animal, auxiliadas por el viento y el agua, constituían los impulsos primordiales en agricultura y manufactura, lo cual provocaba niveles de productividad per cápita muy modestos ${ }^{39}$.

2. Otro nivel más moderno, que incluye procesos mecánicos y más concentrados. Esta parte se refiere igualmente a los mismos sectores que, paralelamente, están utilizando con intensidad la mano de obra en lugar de mecanizar la producción. Es factible pensar que, si bien la máquina de vapor no era desconocida en Mallorca durante la segunda mitad del siglo $\mathrm{xIX}$, a la vez que tampoco lo son los motores de combustión a principios del $\mathrm{xx}$, el peso de esta organización productiva —que suponía apuestas distintas en el campo energético- no fue relevante hasta las primeras décadas del Novecientos, sin que puedan fijarse coordenadas cronológicas estrictas. Las cifras referentes a producción de lignitos en Baleares y las correspondientes a entradas de carbones minerales por el puerto de $\mathrm{Pal}$ $\mathrm{ma}^{40}$, presagian que los elementos propios de una economía inorgánica, con bases claramente minerales, podian dibujarse con cierta transparencia en torno a los años 1920 y no antes, coincidiendo además con la existencia de fábricas de dimensiones respetables. Los datos señalan el escaso consumo de carbones antes de 1900 . En el caso de los lignitos, la mayor parte se dedicaban, en un primer momento, a alimentar las centrales eléc-

\footnotetext{
${ }^{38}$ Memoria Anual de la Cámara de Comercio, Industria y Navegación de Palma de Mallorca, años 1900-1910.

${ }^{39}$ Véase E. A. Wrigley (1989), pp. 89-109 (1993).

${ }^{40}$ Se reproducen en C. Manera (1995).
} 
tricas $^{41}$ (de ahí su avance a comienzos de la centuria); sin embargo, la falta de hullas inglesas fue un aliciente para la producción minera propia. Es precisamente en 1921, en la línea de una clara tendencia al alza en la extracción carbonífera insular, cuando la Cámara de Comercio indicaba que la causa del incremento del consumo en Mallorca se debía a la normalización y el aumento notable de la industria local. Opiniones similares se localizan en las Memorias de la entidad en años posteriores: industrialización y electrificación justifican el importante progreso de los lignitos mallorquines hasta los años $1930^{42}$. El inicio de la crisis mundial provocaba la caída de las importaciones de carbones minerales y de gasolinas, petróleos y aceites para motores diésel. En ese contexto, se mantenían al alza los lignitos mallorquines que, junto a las compras exteriores de carbones y componentes de mayor poder calórico, consolidaban cambios técnicos y cubrían las necesidades energéticas de esa parte de la industria insular cada vez más dependiente de los inputs inorgánicos.

A partir de aquí, el análisis sectorial que se abordará se encuentra muy descompensado y con grandes lagunas. Tales deficiencias obedecen, como es lógico, a la falta de estudios locales sobre la cuestión (piénsese que los temas vinculados al sector secundario se empiezan a plantear con una cierta entidad en Mallorca a partir del año 1987) ${ }^{43}$ y a la orientación seguida por las más recientes contribuciones en historia industrial balear, más escoradas a desvelar la evolución del sector textil en función de la disponibilidad de fuentes de carácter macro y microeconómico. Las parcelas a tratar se ordenan en dos frentes de análisis. En el primero, desglosaré sucintamente aquellos sectores industriales -en concreto, la producción de jabones y de tejidos - que mantuvieron un protagonismo nada desdeñable a nivel estatal y en diferentes momentos, pero que sucumbieron ante el avance de otras comunidades más competitivas. En el segundo, esbozaré el sector del calzado, una actividad enmarcada en crisis y expansiones coyunturales, pero que ha resistido hasta nuestros días el envite de producciones similares en los mismos mercados. Quizás sea éste el último testigo del pasado industrial en una Mallorca plenamente terciarizada.

${ }^{41}$ B. Vaquer (1986), vol. 1, pp. 7-16.

${ }^{42}$ Memoria Anual de la Cámara de Comercio, Industria y Navegación de Palma de Mallorca, años 1921-1931.

${ }^{43}$ Las investigaciones generadas en torno a la revista Estudis d'Història Econòmica marcan, en cierta forma, el inicio de una revisión seria sobre la importancia del sector secundario en la economía mallorquina. 


\subsection{Los sectores que protagonizan el desarrollo industrial}

\subsubsection{El jabón}

La fabricación tradicional de jabón representó, a mediados del siglo XXX, uno de los capítulos más sólidos - y efímeros - en el panorama industrial mallorquín, alzándose hasta 1870 en una obligada referencia para la industria jabonera española. Las primeras noticias sobre una fábrica activa de jabón duro en Mallorca son de 1813, con un capital desembolsado de 22.000 libras mallorquinas (unos 292.000 reales de vellón) ${ }^{44}$. Se trata de una sociedad formada en dicho año por Guillermo Oliver Salvà y la viuda de Brunells e Hijo, como socios mayoritarios, junto a once participantes más entre los que se encuentra Benet Capó Puigserver, cuñado de Oliver Salvà y uno de los comerciantes más poderosos en la Mallorca de la época ${ }^{45}$. En 1829, la planta química mallorquina se distribuía entre una fábrica de jabón fuerte en Palma tres en Alaró y una en Pollença. La capacidad productiva anual estimada de estos centros era de 4.000 quintales. Pero sólo tres años después, las cifras alcanzan una dimensión desconocida: poco más de 27.000 quintales de jabón blando nacen de las empresas insulares ${ }^{46}$. Por consiguiente, todo parece indicar que la expansión jabonera fructificó hacia los años 1830, fortaleciéndose en torno a 1845: las fábricas eran ahora 56, de las cuales 33 producían jabón blando y 24 duro, que por su calidad y baratura de su precio no teme el concurso del tan celebrado jabón de Marsella ${ }^{47}$. El mismo documento precisa que esas 24 fábricas de jabón duro producen, en algunos meses, hasta 12.000 quintales de jabón, cifra descomunal que situaría, de ser cierta, un stock de producción del orden de las 500.000 arrobas (más de 5.000 toneladas). Los datos sobre este sector industrial en Andratx (municipio situado en el extremo occidental de Mallorca, uno de los centros que descollaron en la producción jabonera española en esos años) sugieren que a partir de 1835 Mallorca

44 Si bien existe constancia de la formación de una jabonería en 1811, consagrada a reciclar jabón de piedra extranjero: Arxiu del Regne de Mallorca (ARM), «Real Consulado de Mar y Tierra», caja 50.

45 ARM, «Real Consulado de Mar y Tierra», caja 50. Los datos se cumplimentaron en 1818, cinco años después de creada la empresa. La datación de la misma en Arxiu de la Família Capó, «Secció 1, Documentació comercial», II, núm. 1. Sobre Oliver Salvà, un constitucionalista emprendedor que viajó por buena parte de Europa para aprender técnicas nuevas en la fabricación de jabón y aguardiente, véase E. Lluch (1973), pp. 235 y ss. Sobre Capó Puigserver, C. Manera (1986), pp. 107-130.

46 ARM, «Diputació», núm. 830.

${ }^{47}$ ARM, «Junta de Comerç», caja 45, expediente núm. 562. Citado por A. Pujol (1995). 
empieza a importar cantidades relevantes de aceite y a extraer jabón con gran intensidad y fluidez. Tal aspecto contribuiría a alterar el esquema clásico en el funcionamiento del comercio exterior insular (centrado en exportaciones de aceite e importaciones de cereales), desde el momento en que los inputs necesarios para las jabonerías isleñas se descargan con regularidad y abundancia: los aceites provienen de Cataluña y Andalucía, la sosa de barrilla es de Águilas, Alicante, Almazarrón, Canarias, Cartagena y Tortosa; mientras que los jabones se drenan hacia las costas peninsulares y los mercados americanos. Para la Junta de Comercio, dos factores explicarían este desarrollo sin parangón ${ }^{48}$ : en primer lugar, la superación de la barrera técnica, en el sentido de controlar mucho mejor el proceso productivo gracias al aprendizaje de algunos fabricantes en Marsella; en segundo término, los bajos jornales, que recortarían costes de producción y facilitarían la competitividad del jabón mallorquín.

El dinamismo de la jabonería insular provocó terminantes respuestas por parte de sus más directos competidores. En un informe dirigido en 1841 al Ministerio de Hacienda, Manuel Agustín Heredia, uno de los industriales más emblemáticos de Málaga, observaba con preocupación el desarrollo del jabón balear y su capacidad para penetrar en los mismos mercados en los que los empresarios malacitanos intentaban colocar idénticos géneros. La acusación de fraude no se hizo esperar: un Heredia irritado indicaba que el jabón francés entraba en América como si fuera español, a través de embarcaciones mallorquinas ${ }^{49}$. Si bien no es descartable que se produjeran situaciones como la presentada por el andaluz, la propia reorientación del comercio de Málaga puede dar claves que expliquen la importante captación de los mercados antillanos por los empresarios mallorquines. Como ha sugerido Ramón Ramón, las exportaciones malagueñas de vinos y pasas —que tenían en América su destino prioritario- se empezaron a canalizar hacia Europa, de manera que entre 1844 y 1884 cayeron de un 52 a un 33 por 100 - en términos de valor- las ventas a las colonias desde el puerto de Málaga ${ }^{50}$. Este cierto abandono de los circuitos ultramarinos - actitud que nunca tuvieron los comerciantes mallorquines, que abrieron nuevas vías en las relaciones comerciales con los últimos reductos del Imperio- fue aprovechado por los fabricantes baleares a partir, no debe olvidarse, de una realidad productiva en claro proceso de desarrollo.

48 ARM, «Junta de Comerç», caja 45, expediente núm. 475. Citado por A. Pujol (1995).

49 ARM, «Junta de Comerç», caja 42, expediente núm. 321. Citado por A. Pujol (1995) y por R. Ramón (1993).

${ }^{50}$ R. Ramón (1993). 
En 1856, Baleares se situaba en una posición relativamente preeminente en el sector químico español: la tarifa tercera de las contribuciones industriales otorgaba al archipiélago el 14 por 100 del total ${ }^{51}$. La relevancia de esa cifra es bien patente si se establecen otras comparaciones relativas al ámbito de la circulación. Entre 1861 y 1864 , el 42 por 100 de las exportaciones españolas de jabón se tramitaron desde Palma. Los datos del tráfico de cabotaje no van a la zaga: entre 1857 y 1875 , el 40 por 100 del jabón hispánico se cargaba en el puerto de Andratx ${ }^{52}$. El número de jabonerías se incrementó en esta población, llegando a 16 en 1877. El perfil industrial de la villa era patente. La capacidad total de las calderas, declarada a efectos tributarios, oscilaba entre los 41.600 y 67.600 litros -piénsese que el total español sumaba 109.700 litros 33 -, con una evolución paralela a las extracciones de jabón por el puerto. El éxito de la jabonería en Andratx se sustenta en dos factores esenciales. En primer lugar, en las positivas rentas de localización que le proporcionaba su emplazamiento geográfico privilegiado, en el centro del Mediterráneo occidental, donde la obtención de materias primas - aceite y sosa de barrilla - no era demasiado difícil. En segundo término, por el conocimiento preciso de la demanda americana, al amparo de una política arancelaria proteccionista (y que los fabricantes todavía consideraban insuficiente ${ }^{54}$ ). Ahora bien, a partir de 1865 el empresario barcelonés Marc Rocamora inició una dura fase de acceso y control de los mercados coloniales a partir de una doble estrategia: la incorporación de la sosa artificial para la elaboración del jabón y la modernización del proceso de producción; y la explotación de una tupida red comercial en las Antillas ${ }^{55}$. Los fabricantes de Andratx reaccionaron incorporando el jaboncillo -un álcali procedente de frutos tropicales-, pero penalizaron la calidad del producto. La capacidad demostrada en obtener aceites y barrillas y en competir hábilmente en plazas mercantiles muy concurridas dio paso a la impericia para lograr los inputs que, en el último tercio del siglo XIX, reclamaba la industria jabonera moderna. De diez fábricas existentes en Andratx en 1876 (con una capacidad en sus calderas de 49.500 litros), cuatro años después sólo quedaba una (con 6.500 litros). Mientras esto sucedía, en Barcelona la firma Rocamora se colocaba, en 1886, en decimoquinto lugar en el ranking de las cincuenta

\footnotetext{
"J. Nadal (1987), p. 52.

52 R. Ramón (1993), pp. 35-36.

33 R. Ramón (1994), p. 153.

${ }^{54}$ Véase ARM, «Junta de Comerç», caja 45, expediente núm. 497.

5 R. Ramón (1994), pp. 151-162.
} 
primeras empresas de Sant Martí de Provençals, con una cuota fiscal declarada de 2.509 pesetas ${ }^{56}$. El triunfo del Principado era, por tanto, evidente en un sector cuyo liderazgo fue mallorquín durante muchos años.

\subsubsection{El textil}

Es difícil evaluar en términos cuantitativos el progreso del sector textil en Mallorca. Las fuentes escurren informaciones valiosas e impiden una comparación más o menos homogénea de las diferentes variables que deben contemplarse para un acercamiento preciso ${ }^{57}$. Los datos, aunque muy incompletos - pecan a la baja sobre todo para el período 1856-1931, a tenor de referencias archivísticas municipales- sugieren dos aspectos. Primeramente, el sector inicia su mecanización precozmente (1847), si bien la extiende en fechas muy tardías; con un cierto vigor, desde comienzos del Novecientos. La precariedad de las variables se advierte, como mínimo, en un caso concreto, En 1856 figura en las Estadísticas de la Contribución Industrial y de Comercio la ridícula cifra de 28 telares mecánicos de algodón para Baleares, cuando se sabe que en ese año ya existía una gran fábrica de tejidos de algodón en Palma, Villalonga, Barceló y Cía., con más de 100 telares. En 1922, las mismas Estadísticas de la Contribución Industrial $y$ de Comercio consignan 180 telares mecánicos de lana y otras fibras (con la excepción del algodón) para todas las islas, mientras solamente en la fábricas de Esporles había 114 telares mecánicos de lana declarados en $1927^{58}$. En segundo lugar, pervive - y esto es muy importante- el trabajo de carácter tradicional, muy intensivo, incorporando campesinos y artesanos a determinadas fases de la producción (tejido manual e incluso tintado ${ }^{59}$ ), compaginándolas con las labores que se desarrollaban en la fábrica.

Una característica central define el desarrollo del textil mallorquín: el avance gradual del algodón junto a la importante pervivencia de la lana, progresos ambos que se certificarán de manera rotunda a partir de 1830 . Todo ello ya apunta un hecho significativo: el proceso de desplazamiento -que no quiere decir sustitución absoluta - del lino por el algodón, al menos en Palma y Sóller. Ello se aprecia en la reconversión al algodón

56 J. Nadal y X. Tafunell (1992), p. 302.

57 Todos los indicadores que se han podido reconstruir para el período 1784-1931, en C. Manera (1995).

58 J. M. Escartin (1993), p. 160.

${ }^{59}$ C. Manera y J. Roca (1994). 
de antiguos telares que trabajaban con materias primas más tradicionales; es decir, se asiste a una inversión, limitada pero perceptible, en capital fijo lo que se relaciona con la pretensión de los fabricantes en producir géneros de notable demanda en el mercado interior $\mathrm{y}$, esencialmente, en el exterior. La mecanización del textil contribuye a consolidar esa práctica. En efecto, estamos en una fase en la que su vértice más cualitativo es la aplicación del vapor: 1847 marca un punto de arranque cuando esa energía se acopla, recuérdese, a una fábrica de hilados de algodón, Villalonga Barceló y Cía. El algodón se convierte así en una rama puntera en el proceso de «modernización» del tejido industrial. Esta capacidad de arrastre se refleja en la población activa: la manufactura algodonera absorbe el 53 por 100 de los trabajadores fabriles de las islas en 1861, mientras son muy reducidos los porcentajes alcanzados por la lana, el lino y, sobre todo, la seda ${ }^{60}$. Ahora bien, conviene apuntar que ello no equivale a un declinar imparable de los tejidos de lino y cáñamo, habida cuenta que las cifras de salidas por el puerto de Palma de esas mercancías son considerables a partir, esencialmente, del último tercio del Ochocientos. La industria fundamentada en las materias primas más tradicionales pervive, por tanto, junto a la más innovadora auspiciada en el algodón.

Los guarismos de la contribución industrial de 1856 referidos a Baleares manifiestan el dominio al que se aludía. El número de telares comunes dedicados al algodón es mayoritario (908, a los que hay que añadir 28 telares mecánicos), frente a los vinculados más directamente a las viejas manufacturas (161). La producción de tejidos de algodón parece, pues, enraizarse en el archipiélago a lo largo de la segunda mitad del Ochocientos, si se tiene en cuenta que las islas son una de las pocas provincias que figuran con factores particulares de dicha manufactura: husos $(6.030$, el 9 por 100 del total nacional, con la exclusión de Barcelona) y telares (936, el 23 por 100 , siempre con la citada excepción). Dicha industria se nutre de unas materias primas determinadas. La primordial, el algodón, se importa de Nueva Orleáns y Puerto Rico, siendo necesarias 562.500 libras para el funcionamiento de los casi 2.000 telares existentes en Mallorca hacia 1870. Los inputs secundarios son el cáñamo (que se cultiva en la isla), el lino (de cosecha propia y también introducido de Génova), el hilo de lino (cargado en puertos ingleses) y añiles y palos (registrados en las Antillas). El valor anual de la producción algodonera puede oscilar entre 10 y 20 millones de reales, según cálculos de la Sociedad Económica Mallorquina

${ }^{\infty}$ F. Giménez Guited (1862). 
de Amigos del País y de Francisco Giménez Guited ${ }^{61}$. Pero ello no implica que el algodón haya reemplazado absolutamente las materias primas tradicionales. Por el contrario, la manufactura más ancestral se sigue trabajando bajo formas de industria domiciliaria y, en pocas décadas, conocerá las pautas productivas marcadas desde las fábricas. Lo que quiere subrayarse es que las manufacturas de estambre, cáñamo, lana y lino, mezcladas con algodón, seguían siendo determinantes, ya bien entrado el siglo XIX, en el marco de las economías familiares. Los datos sobre el tráfico del comercio de cabotaje por el puerto de Palma entre 1857 y 1920 confirman esa aseveración. Estas variables ilustran el crecimiento de los tejidos de lana, con un progreso visible también desde $1860 \mathrm{y}$, sobre todo, a partir de 1883 , de manera que se convierte - hasta 1912 - en el primordial renglón de las salidas textiles. La evolución del subsector lanero es más espectacular que la del algodón, aunque este último apunte una tendencia creciente a raíz de 1898 hasta las vísperas del estallido de la Primera Guerra Mundial. De hecho, las salidas de tejidos de algodón son las únicas que distinguen un patente crecimiento con el advenimiento del nuevo siglo, frente al reflujo relativo de las de lana, lino, cáñamo y yute ${ }^{62}$. Pero el textil lanero, en el cual se incluyen las mantas, es el único que evidencia salidas netas en el comercio de cabotaje por el puerto de Palma, con escasos años en que las entradas albergan un mayor volumen que los despachos hacia el exterior.

En conjunto, el textil avanzaba desde 1865 , con un período de débil desarrollo hasta 1880 , para obtener una mayor aceleración a partir de esta última década. De hecho, crecen las extracciones de todos los tejidos en cantidades que permiten afirmar que el esfuerzo exportador $-\mathrm{y}$ productivo - se canaliza hacia el conjunto de los subsectores, y no sólo en relación a uno de ellos. Por consiguiente, el textil mallorquín también cuenta con su particular cuota de mercado, y los empresarios no descuidan esa realidad: los más arriesgados y perspicaces se decidirán, a partir de la década de 1880, a invertir en la remodelación de maquinaria y edificios. La concentración del capital industrial será un hecho claro en estas coordenadas de impulso económico y dinamismo mercantil. Pero la fuerte competencia de los tejidos catalanes será, a lo largo del primer tercio del Novecientos, el principal escollo al que deberán enfrentarse los industriales textiles

${ }^{61}$ ARM, «Sociedad Económica Mallorquina de Amigos del País», caja 33, expediente núm. 23; F. Giménez Guited (1862).

62 Las cifras en C. Manera (1995). 
SALIDAS NETAS DE TEJIDOS DE LANA POR EL PUERTO DE PALMA

Kgrs.

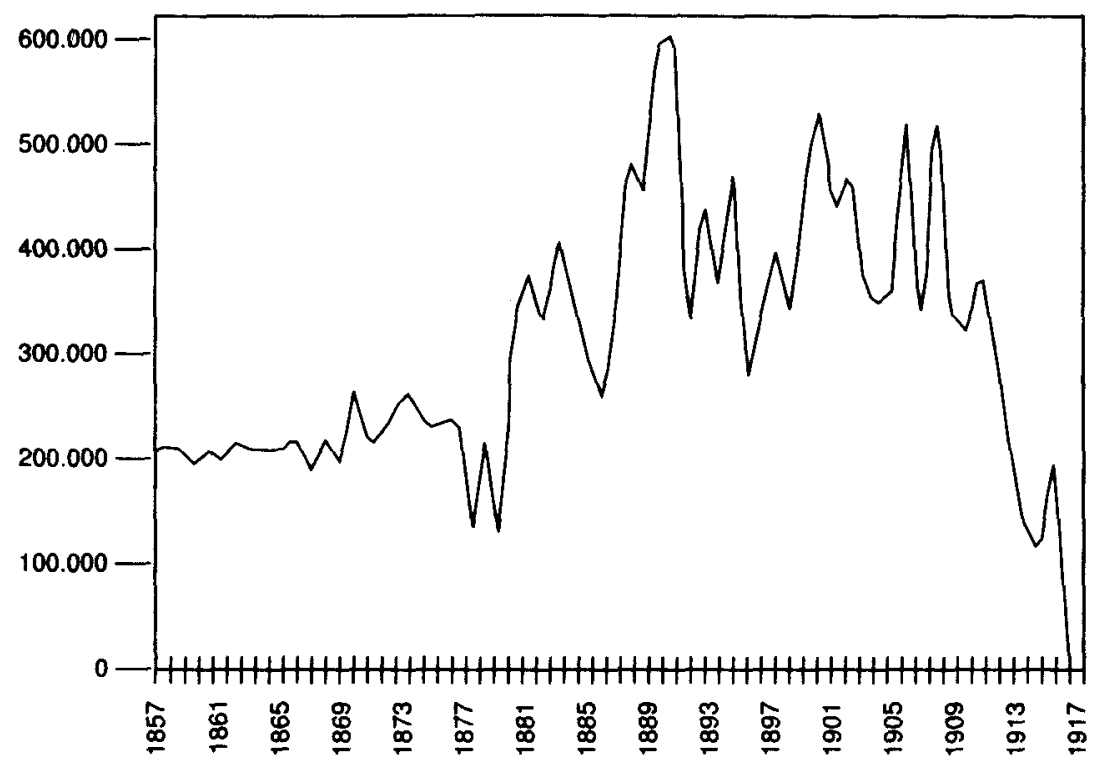

FuENTE: Estadisticas del Comercio de Cabotaje.

mallorquines, protagonistas de un sector que languidecerá, sobre todo, a partir de los años 1960.

\subsubsection{El calzado}

En Mallorca, la fabricación de calzado se coloca en posición eminente en el conjunto de la industria balear. Esta expansión obedece principalmente a dos causas:

a) Los bajos costes de producción del zapato mallorquín en relación al americano, su primordial competidor. Esto es debido a los reducidos salarios que regulan el sector. Los cálculos que se han podido establecer son explícitos, referidos a 1900. Los costes de fabricación en el proceso manual se concretan en 3,9 pesetas para el calzado más basto y 5,5 para 
el mejor acabado; la participación de las máquinas incide recortando el valor de la fuerza de trabajo: el oficial zapatero obtiene ahora sesenta céntimos menos por cada par de zapatos ordinarios, y ochenta céntimos en el caso de los finos. Por otra parte, los gastos generales de las fábricas son difíciles de evaluar, dado que dependen de la capacidad del empresario y de su capital; sin embargo, Francisco Durán, el inquieto ingeniero que redactó la Memoria sobre la fabricación de calzado en la provincia de Baleares propone un 15 por 100 para la manufactura a mano y un 30 por 100 para la mecanizada. El conjunto de esos renglones, más los valores medios de venta, permite intuir los beneficios resultantes de cada uno de los pares de zapatos. Cabe comprobar cómo el rédito líquido en el caso manual es de 1,5 pesetas, es decir, en torno al 23 por 100; el concurso de las máquinas representa beneficios de 1,7 pesetas, casi el 27 por 100 . La diferencia citada no es demasiado elevada: las ventajas de un menor coste salarial se contrarrestan por unos gastos generales mayores librados por las empresas que incorporan la mecanización de los procesos productivos.

La baratura del factor trabajo evita así el incremento de inversiones en capital fijo: la integración de nuevos trabajadores a la producción, cuando la demanda exige elevar los stocks, se convierte en la solución adoptada por los empresarios. Las diferentes configuraciones que adopta el proceso productivo, centradas sobre todo en la elaboración manual, posibilitan la intervención de una numerosa fuerza laboral, de manera que la estrategia empresarial puede excluir, sin problemas insalvables, la inversión en máquinas. Esto explica que las instalaciones mecánicas para la fabricación del calzado sean más bien escasas en Baleares, hecho que contrasta con los datos sobre producción, cifrados entre un millón y medio y dos millones de pares de zapatos anuales ${ }^{63}$. De hecho, la mecanización del calzado fue muy tardía en Mallorca: según Jordi Nadal, en 1912 existían en Baleares diez fábricas de zapatos producidos por medios total o parcialmente mecánicos (una en Binissalem, dos en Ciutadella, dos en Palma y cinco en Maó), que generaban un total de unos 415.000 pares de zapatos. Esto significaba poco más del 8 por 100 de la producción española (Baleares era la cuarta región después de Cataluña, País Valenciano y Murcia) y casi un 30 por 100 del calzado elaborado en las islas. El peso del sistema

${ }^{63}$ F. Durán (1900), p. 359. Este ingeniero declara que en 1899 se confeccionaron 1.594.928 pares de zapatos en Baleares por un valor de 10.494.626 pesetas, correspondiendo a Menorca 6.113.695 pesetas y 4.580.931 a Mallorca. 
tradicional de producción -el 70 por 100 restante-, intensivo en fuerza de trabajo, es bien notorio ${ }^{64}$.

b) Las distintas formas de organización laboral. La industria del calzado certifica, una vez más, la práctica paralela de mecanismos de elaboración bien dispares, modernos y tradicionales, dado que botas y zapatos se elaboran bajo tres formas concretas:

- fabricación de todo tipo de calzado mediante máquinas y herramientas, con concentración de trabajadores en un solo edificio;

- fabricación manual con las mismas condiciones anteriores;

- fabricación también manual, pero definida por la flexibilización del proceso productivo, de forma que se sigue con las fórmulas clásicas de la industria domiciliaria.

En los casos de producción manual se llega a estados claros de industria sumergida, dada su mayor capacidad de movilidad: los cambios de domicilio o la dispersión laboral son procedimientos desarrollados con el fin de esquivar la tributación. Es ésta una de las preocupaciones máximas de los ingenieros industriales que tratan de presentar dinámicas alternativas en las declaraciones fabriles, con el objetivo de incrementar las cotizaciones empresariales al erario público. Estos fraudes afectan igualmente la distribución: los fabricantes de calzado disponen frecuentemente de testaferros en las exportaciones, de manera que también en la esfera de la circulación se articulan todo tipo de estratagemas para impedir la identificación del empresario. En este sentido, la desesperación de Francisco Durán se deja sentir sin ambages en sus continuos comentarios sobre las trampas ejecutadas por los industriales ${ }^{65}$. Incluso los zapateros, que tri-

${ }^{64} \mathrm{~J}$. Nadal (1994), pp. 321-339. El dato en p. 332, cuadro 10.2. La significación de la actividad artesanal, domiciliaria, se enfatiza en otros casos emblemáticos del calzado en España, como Elda y Elche. Véase J. M. Bernabé (1975), pp. 65-89. Es modélico el tratamiento del caso ilicitano en el excelente estudio de J. A. Miranda (1991). Cabe advertir que, incluso en las primeras etapas del desarrollo de la poderosa industria del calzado en Estados Unidos, la flexibilización en la producción y el trabajo domiciliario constituyeron estrategias muy frecuentadas por los empresarios; cf. W. H. Jr. Mulligan (1981).

65 F. Durán (1900), pp. 363-364. Efectivamente, cuando el calzado mecaniza su proceso de producción y, por tanto, necesita edificios especiales, hay pocas posibilidades de que se pueda huir de la acción investigadora, si bien se dan casos que pueden resultar sorprendentes. Por ejemplo, Durán menciona que en Palma existe una fábrica de calzado, propiedad de José Garau, que ha renovado toda su maquinaria y que confecciona mil pares de zapatos al día. Pero a continuación el ingeniero expone que en Sóller, Llucmajor y Maó se erigen tres centros fabriles que, a pesar de trabajar con el auxilio de máquinas, desconocemos su importancia, pues ni siquiera éstas figuran en matricula como tales a mano. Ahora bien, cuando la manufactura se fabrica manualmente y con un número de obreros reducido, 
butan en la tarifa 4 (es decir, la de Artes y Oficios), quebrantan constantemente sus relaciones fiscales ${ }^{66}$.

Esa búsqueda de flexibilidad en la relación capital/trabajo se destaca esencialmente ante una situación de demanda elástica y, de manera específica, en períodos de crisis. La tendencia a la descentralización no puede entenderse sólo como una respuesta a las oscilaciones a la baja de la deman$\mathrm{da}$, aunque incrementos limitados o sin perspectiva de continuidad en aquélla puedan conducir, para mantener la cuota de mercado, a aumentar la capacidad productiva de forma descentralizada en lugar de alcanzar un proceso de innovación tecnológica. Esta dispersión es menos complicada en aquellas producciones en las que la concentración no genera necesariamente economías de escala y, por consiguiente, la disminución de los costes medios unitarios. El calzado mallorquín manifiesta un ciclo productivo fluctuante, discontinuo y poco integrado, lo cual significa la posibilidad de fragmentar fases de un proceso de producción definido por una estructura muy coyuntural.

Las áreas de mercado para el calzado balear se focalizan en el propio espacio nacional, Cuba, Marruecos y en dos países que, durante la guerra iniciada en 1914, alcanzarán gran importancia para el zapato balear: Alemania y Francia. Ahora bien, el puerto de Barcelona se convierte en cabecera crucial en el tráfico mallorquín de esa mercadería: en prácticamente el 90 por 100 de los envíos hacia aquella ciudad se indica que se trata de transbordos cuyo destino final son las Antillas, Filipinas y repúblicas suramericanas ${ }^{67}$. En cuanto a las relaciones con la Península Ibérica, la siguiente gráfica perfila la evolución de las salidas del producto acabado, en expresiones netas.

Se identifican dos fases en las extracciones de calzado. La primera (1859-1891) es de claro crecimiento, con una suave tendencia al alza entre 1859 y 1886 para dar paso a una corta pero espectacular etapa de fuerte expansión hasta 1891. Las estrategias de los empresarios parecen ajustarse a las diferentes demandas, de manera que en esos años el calzado mallorquín ha conquistado claramente parcelas importantes del mercado. La segunda (1892-1920), mucho más irregular, atestigua la importante caída entre 1892 y 1899 , con los conflictos coloniales como telón de fondo que,

\footnotetext{
se acrecientan las dificultades de control para la Hacienda Pública, toda vez que al menor problema se dispersan las diferentes fases productivas, pasando a ejercer [los empresarios] su industria a un barrio extremo.

*6 F. Durán (1900), p. 375.

67 F. Durán (1900), pp. 357-358.
} 


\section{SALIDAS NETAS DE CALZADO POR EL PUERTO DE PALMA}

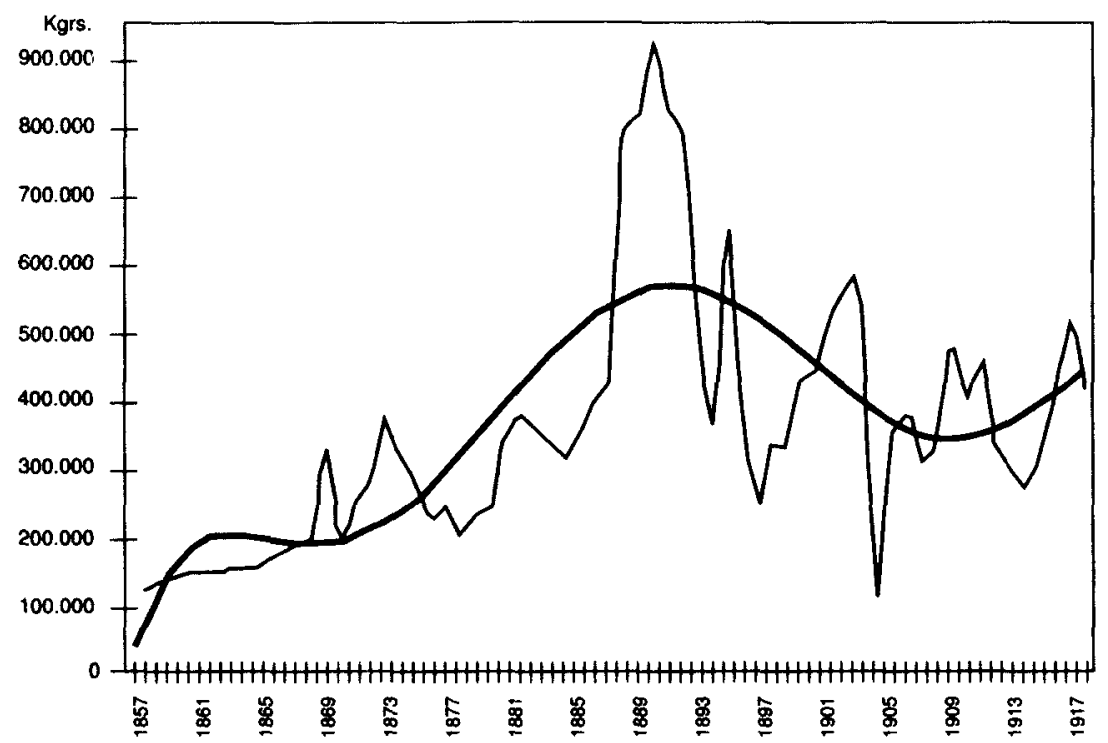

FUENTE: Estadísticas del Comercio de Cabotaje.

sin duda, fueron responsables de la contracción de las ventas; la tendencia se corrige a comienzos del nuevo siglo y mantiene una cierta regularidad hasta fines de la Gran Guerra, coyuntura considerada siempre como muy propicia para los despachos de calzado. Las dos fases presentadas no mantienen una relación demasiado clara con las entradas de las materias primas perentorias para la fabricación de zapatos, especialmente cueros y pieles. Entre 1857 y 1897 , esas introducciones no siempre fueron netas, conocieron claras irregularidades y pocas veces superaron las 250 toneladas; en cambio, entre 1898 y 1920 los cargamentos se hacieron más estables, siempre con saldos netos.

Ahora bien, según informaciones de la propia Cámara de Comercio, a comienzos de la Primera Guerra Mundial —en concreto, entre 1914 y 1915 - las extracciones de botas y zapatos aumentan poco más del 20 por 100 en términos físicos, si bien doblaban su valoración en pesetas ${ }^{68}$. Sólo crecen calzado, suelas y almendrón; a la par que, en los valores apor-

${ }^{68} B C O C I N(1915,1916$ y 1917). 
tados por la citada institución empresarial, el calzado significa, durante los primeros años del conflicto, entre el 16 y el 32 por 100 de las mercancías registradas por el puerto de Palma, si se cotejan las cifras anteriores con las referentes a la coyuntura de la Gran Guerra (1913-1923) ${ }^{69}$. Sin embargo, debe destacarse que los datos sistematizados sobre comercio de cabotaje no apoyan la tesis de un gran crecimiento en las ventas de botas y zapatos durante las hostilidades europeas, con la única excepción del año 1915. De hecho, pocos meses antes de los sucesos de Sarajevo los propios empresarios manifestaban el estado de postración del sector. En efecto, la crisis del calzado dará pábulo a la publicación, en el boletín de la Cámara de Comercio, de ácidos comentarios protagonizados por conocidos industriales ${ }^{70}$. Para los empresarios, la pérdida de las colonias representaba la causa principal de la recesión; las siguientes palabras son elocuentes en tal sentido: vino la decadencia obligada de la industria (...) del calzado mallorquin, que puede decirse que, dentro de la fabricación nacional, era principalmente el que explotaba aquellas plazas ${ }^{71}$. Esto significó, según los industriales, la necesidad de canalizar las operaciones con el mercado ibérico, fuertemente competitivo dada la concurrencia de artículos similares a los producidos en las islas, pero elaborados en otras regiones con procesos mecanizados. Así pues, el impacto negativo de la pérdida de los últimos dominios americanos no es despreciable, a tenor de lo expuesto por los empresarios. Dicho de otro modo: los puertos españoles, que probablemente actuarán como redistribuidores hacia el extranjero del calzado mallorquín, son ahora los que más interesan a los fabricantes insulares, de forma que sitúan en un segundo nivel las conexiones directas con los mercados internacionales. La demanda nacional acicateó el auténtico despegue en la producción de calzado en Mallorca a partir de los años 1930 y, sobre todo, a raíz de la guerra civil. Las cifras alcanzan magnitudes de impresión: la Cámara de Comercio declaraba que en 1937 unos 4.000 obreros elaboraban poco

69 BCOCIN (1913-1923).

${ }^{70}$ Se comenta que la producción de botas y zapatos es el sostén de una quinta parte de sus babitantes (de Mallorca y Menorca), BCOCIN (1913), pp. 174-177. La población obrera mallorquina se puede cifrar así: 24.744 personas en 1914, 29.043 en 1920 y 20.075 en 1925; cf. R. Molina (1990), p. 38. Poco más de 5.000 personas se dedicarían, pues, a la industria del calzado en 1913.

${ }^{7}$ En su texto de 1900 , ya conocido, Francisco Durán apuntaba que el 90 por 100 del calzado fabricado se exportaba a las Antillas, Filipinas y América del Sur, por cuya razón, en el año 1898, durante la guerra con los Estados Unidos, sufrió esta industria una tremenda crisis que la amenazó de muerte, cerrándose algunas fábricas y emigrando sus obreros en busca de trabajo a otras provincias y al extranjero, y particularmente Marsella, que esta industria está alimentada por obreros de Baleares, F. Durán (1900), pp. 356-357. 
más de un millón y medio de pares de botas y zapatos (la demanda militar fue trascendental en esta coyuntura), valorados en 31 millones de pesetas; dos años después, ya son tres millones de pares fabricados por siete mil trabajadores, que representan 75 millones de pesetas ${ }^{72}$. Guerra y calzado tuvieron aquí una enorme sincronía, significando la firme consolidación del sector.

\section{PORCENTAJES QUE REPRESENTAN CALZADO Y TEJIDOS DE LANA SOBRE EL TOTAL DE SALIDAS DEL PUERTO DE PALMA} (VALORES)

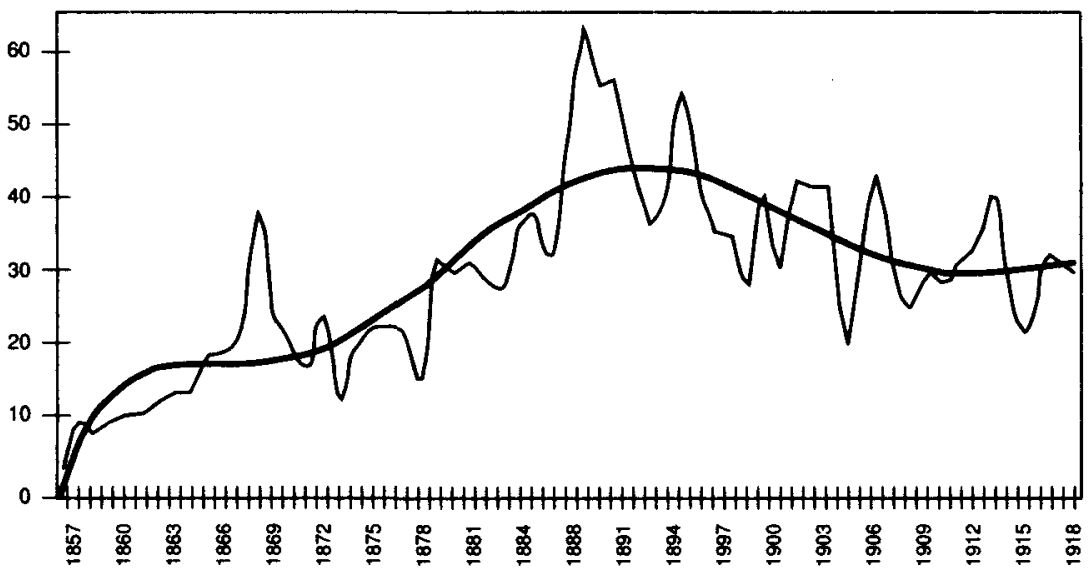

FuENTE: Estadistica del Comercio de Cabotaje.

Esta relevancia no es meramente coyuntural, toda vez que una ampliación de la cronología ratifica la importancia de producciones industriales como el calzado y los tejidos de lana (tal vez los dos sectores clave de la industria mallorquina), que presentan un saldo neto y regular, en kilogramos, en las salidas por el puerto de Palma. Si en lugar de operar con las variables de peso ya conocidas para las dos mercancías citadas lo hacemos con los valores expresados en sus términos relativos, los resultados constituyen un indicador plausible sobre la significación de zapatos y telas de lana sobre el total de las extracciones de cabotaje. Recuérdese que

${ }^{72}$ Memoria Anual de la Cámara de Comercio, Industria y Navegación de Palma de Mallorca, años 1937 y 1939. 
este régimen mercantil es el más importante, a gran distancia, en las relaciones comerciales de Mallorca.

Es importante remarcar que a partir de 1880 (y con la única excepción de 1906), los porcentajes superan el 20 por 100 y en muchos años el 40 por 100 . Estos datos son conclusivos sobre la relevancia de esta industria para la economía mallorquina, sustentada sobre sectores no líderes y con el encuadre de una industrialización europea que también se desarrollaba a partir de esas actividades no pautadoras. La presencia mercantil sirve de corolario a una realidad productiva incuestionable que matiza notablemente la visión tradicional de la evolución económica insular. Estos resultados ya no deberían ser desdeñados por más tiempo.

\section{CONCLUSIÓN}

A partir de lo expuesto, se apuntan tres reflexiones de carácter general que, a su vez, delinean nuevos escenarios para la investigación:

1. La inserción de claros mecanismos mercantiles en la estructura tradicional —al margen del tráfico vinculado a granos y aceites-, en los que el protagonismo de los sectores sociales más modestos fue evidente, representa un proceso que se confirma, en diferentes momentos, a lo largo del Ochocientos. El caso más emblemático es la expansión vitícola, que se había desarrollado sobre todo desde 1730 en Felanitx, en la zona oriental de la isla, con el aguardiente como renglón primordial. El comercio del licor provocó la arquitectura de una compleja red mercantil que partía del pequeño productor y se culminaba en las remesas de destilados exportados desde Palma, hacia Europa y América, por los grandes comerciantes. Esas infraestructura y experiencia fueron determinantes en el último tercio del siglo XIX, cuando el vino se tradujo en una de las divisas más importantes de Mallorca y provocó, antes del ocaso imbuido por la filoxera, un crecimiento económico aparentemente muy sólido. Al mismo tiempo, los cítricos se convertían en un claro factor de desarrollo en el valle de Sóller, en el corazón de la cordillera norte, y su negociación tejía a su vez una red comercial que se afianzaba en el sur de Francia ${ }^{73}$.

2. En otros lugares del campo mallorquín, algarrobos, almendros e higueras expandían sus áreas de cultivo y también integraban sus producciones en los circuitos comerciales, hasta el punto de que almendrones

${ }^{73}$ Véase C. Manera (1995). 
y algarrobas sumaban constantes demandas por parte de los mercados francés e inglés. La competitividad de esta agricultura en contacto fluido con el mercado subraya el cambio en el modelo agrario conocido hasta los primeros años del siglo XIX. Esa transformación supone un paisaje más diversificado, con profusión de cultivos que no necesariamente se vinculan a la gran propiedad - como los olivos y los cereales- y que ostentan una cuota cada vez más importante en el producto agrario total. Al mismo tiempo, la nueva orientación de la agricultura mallorquina activaba experiencias manufactureras e industriales concretas, desde la existencia de talleres mecánicos consagrados a la fabricación y adaptación de máquinas y herramientas para el agro, hasta el inicio de las empresas conserveras de frutas y verduras. Modestamente, pero con seguridad, agricultura e industria se entrelazaban. La actitud empresarial resultó esencial para que esto se produjera.

3. Algunas actividades industriales (calzado, conservas alimenticias, jabón, tejidos de lana) demostraron una capacidad innegable para ajustarse a los mercados. De hecho, entre 1860 y 1930 más de una cuarta parte - llegando hasta cifras regulares en torno al 30-40 por 100 — de los valores de las mercancías extraídas por el puerto de Palma eran productos manufacturados (mantas y otros tejidos de lana, zapatos). Este mundo industrial se componía de una importante franja artesanal coexistente con la formación de la fábrica y la utilización de los vectores energéticos de la industrialización. Sin embargo, los fabricantes priorizaron la flexibilización e intensificación de la fuerza de trabajo sobre la mecanización de los procesos productivos. De hecho, ésta fue la estrategia principal que, en términos generales, adoptaron los empresarios en el conjunto de una industria representada por sectores no líderes y vertebrada en pequeñas unidades de producción, en las que la fuerza laboral se caracterizaba por su pluriactividad. Lo cual demuestra un conocimiento preciso del mercado de trabajo por parte de los industriales. En tal sentido, debe matizarse la idea, demasiado vigente, de la inexperiencia empresarial hasta el acceso al turismo de masas. Al lado de los caciques rurales - cuyas actividades económicas deberían estudiarse con mayor detenimiento, para huir también de imágenes estereotipadas--, empresarios industriales y agrícolas desarrollaron sus proyectos bajo formas organizativas y estrategias económicas similares a las impulsadas por sus homólogos europeos. 


\section{BIBLIOGRAFÍA}

Alemany, L. (1973), «Notas para una pequeña historia de la banca balear», en autores diversos, Banco de Crédito Balear, 1872-1972. Primer centenario (Palma). Alenyar, M.; BarCeló, B., y Carlos, P. (1982), «Evolució econòmica», en B. Barceló (dir.), Cent anys de la bistòria de les Balears, Caixa d'Estalvis de Balears (Palma).

Álvarez, R. (1896), Anuario de la Bolsa, del Comercio y de la Banca (Madrid). Aymard, M. (1983), «Autoconsommation et marchés: Chayanov, Labrousse ou Le Roy Ladurie?», Annales, núm. 6.

BALLESTER, A. (1922), Resumen estadístico de la producción agrícola en Baleares, Archivo de la Delegación del Ministerio de Agricultura, Palma.

Barceló, B. (1962), «Evolución de la población en los municipios de la isla de Mallorca», Boletín de la Cámara Oficial de Comercio, Industria y Navegación, núm. 637 (Palma).

- (1964), El segle XIX a Mallorca, Obra Cultural Balear (Palma).

- (1993), «La decadencia de las actividades agrarias en las Baleares», en A. GiL Olcina y A. Morales (ed.), Medio siglo de cambios agrarios en España, Diputación Provincial de Alicante (Alicante).

BERG, M. (1987) La era de las manufacturas. Una nueva historia de la Revolución industrial británica, Crítica (Barcelona).

Bernabé, J. M. (1975), Indústria i subdesenvolupament al País Valencià. El calçat a la Vall del Vinalopó, Moll (Palma).

CARBonero, M. A. (1987), «Estructura territorial del sòl rural», en R. PiÉ (dir.), Estudi sobre les parcel lacions, assentaments $i$ nuclis de població en el sòl urbanitzable $i$ no urbanitzable, Ajuntament de Palma (Palma).

CARRETERO, E. (1875), Estado de la agricultura en esta provincia, Archivo de la Delegación del Ministerio de Agricultura, Palma.

DE VRIES, J. (1987), La urbanización de Europa, 1500-1800, Crítica (Barcelona).

DURAN, F. (1900), «Memoria sobre la fabricación de calzado en la provincia de Baleares», en Memorias sobre la industria fabril, redactadas por los ingenieros al servicio de la investigación de la Hacienda Pública, Ministerio de Hacienda (Madrid).

Escartín, J. M. (1993), Manufactura i induistria tèxtils a Mallorca: els casos de la seda $i$ de la llana, Tesis de licenciatura, Universitat de les Illes Balears, inédita.

ESTELRICH, P. (1900), Guía práctica para la aplicación de abonos químicos o minerales con las fórmulas calculadas para los terrenos de las Baleares, Imprenta Vidal Hermanos (Barcelona).

FERnández Fuster, L. (1991), Geografía general del turismo de masas, Alianza Universidad (Madrid).

FontanA, J. (1974), La quiebra de la Monarquia absoluta, 1814-1820, Ariel (Barcelona).

- (1985), «La crisis agraria de comienzos del siglo XIX y sus repercusiones en España", en A. GARCIA SANZ y R. GARRABOU (ed.), Historia agraria de la España contemporánea, Crítica (Barcelona).

GarCIA, A., y GuÁRDIA, M. (1987), «Transició i ciutat: les transformacions de l'estructura de l'espai», Manuscrits. Revista d'Història Moderna, núms. 4/5. 
GARCí SANZ, A. (1985), «Crisis de la agricultura tradicional y revolución liberal», en A. Garcia Sanz y R. Garrabou (ed.), Historia agraria de la España contemporánea, Crítica (Barcelona).

GIMÉNEZ GuITED, F. (1862), Guía fabril e industrial de España (Madrid-Barcelona). JONES, E. (1974), «Los orígenes agrícolas de la industria», en AUTORES DIVERSOS, Agricultura y desarrollo del capitalismo, Anagrama (Madrid).

KRIEDTE, P.; MEDICK, H., y SChlumbOHM, J. (1993), «Proto-industrialization revisited: demography, social structure and modern domestic industry», Continuity and Change, $8,2$.

LLOPIS, E. (1985), «Algunas consideraciones acerca de la producción agraria castellana en los veinticinco últimos años del Antiguo Régimen», en A. GarCíA Sanz, R. Garrabou (ed.), Historia agraria de la España contemporánea, Crítica (Barcelona).

LLUCH, E. (1973), El pensament econòmic a Catalunya (1760-1840). Els origens ideològics del proteccionisme $i$ la presa de consciència de la burgesia catalana, Edicions 62 (Barcelona).

MAGER, W. (1993), «Proto-industrialization and proto-industry: the uses and drawbacks of two concepts», Continuity and Change, 8, 2.

MANERA, C. (1986), «Burgesia comercial mallorquina i mercat americà (l'evolució econòmica del mercader Benet Capó i Puigserver)», en AUTORES DIversos, Quinze anys dels Premis d'Investigació "Ciutat de Palma" (1970-1984), Ajuntament de Palma (Palma).

MANERA, C. (1990), «Resistir i créixer. Canvi econòmic i classes socials a la Mallorca del segle XVII», Randa, núm. 26.

Manera, C. (1995), Desarrollo económico y actitudes empresariales en la Mallorca contemporánea, 1730-1930. Rasgos económicos esenciales de una sociedad preturística, Memoria de Doctorado en Ciencias Económicas, Facultat de Ciències Econòmiques i Empresarials, Universitat de les Illes Balears, inédita.

Manera, C., y Petrus, J. M. (1991), «El sector industrial en el creixement econòmic de Mallorca, 1780-1985», en C. Manera y J. M. Petrus (coord.), Del taller a la fabrica. El procés d'industrialització a Mallorca, Ajuntament de Palma (Pal$\mathrm{ma}$ ).

MANERA, C., y ROCA, J. (1994), «Commercial conjunction and industrial enterprise in Majorca. First writing of a study about the enterprise Can Ribas, 1870-1914», Conference on Business History (Rotterdam), inédito.

MarTíN, M. (1989), «Evolución de las disparidades regionales: una perspectiva históricam, en J. L. GarCía DelGado (dir.), España, economia, Espasa-Calpe (Madrid).

Martinez Cortiña, R. (1990), La transición económica de España, Ediciones Ciencias Sociales (Madrid).

MiKelARENA, F. (1993), «Los movimientos migratorios interprovinciales en España entre 1877 y 1930: áreas de atracción, áreas de expulsión, periodización cronológica y cuencas migratorias», Cuadernos Aragoneses de Economía, vol. 3, núm. 2.

Miranda, J. A. (1991), Hacia un modelo industrial. Elche, 1850-1930, Instituto de Cultura Juan Gil-Albert (Alicante). 
MolinA, R. (1990), «Indústria i força de treball a començaments del segle xx. El cas mallorquí: una reflexió entorn a la formació del proletariat modern», Estudis d'Història Econòmica (1990-1).

Mulligan, W. H. Jr. (1981), «Mechanization and work in the American shoe industry: Lynn, Massachussets, 1852-1883», The Journal of Economic History, vol. 41 , núm. 1.

NADAL, J. (1994), «La transición del zapato manual al zapato "mecánico" en España», en J. NaDAl y J. Catalán (ed.), la cara oculta de la industrialización, Alianza Universidad (Madrid).

Nadal, J., y Tafunell, X. (1992), Sant Martí de Provençals, pulmó industrial de Barcelona (1847-1992), Columna (Barcelona).

PASCUAL, P., y SUdRiÀ, C. (1992), «Quiebra colonial y ajuste monetario en España», Estudis d'Història Econòmica (1992-2).

PenYa, A. (1990), «Tallers, obradors i fàbriques. Aproximació a la indústria a Palma durant el segle XIX», Estudis d'Història Econòmica (1990-1).

PENYA, P. D'AlCÀntARA (1884), La industria mallorquina. Consideraciones generales sobre su estado actual y mejoras que reclama, Imprenta de Gelabert (Palma).

PIERAS, G. (1884)), «El procés d'industrialització a Inca i l'organització del temps de treball», en Actas de las I Jomades d'Estudis Locals (Inca).

Pujol, A. (1995), «La indústria del sabó a Andratx», comunicación presentada en el VII Seminari d'Història Econòmica (Palma), inédito.

RAMÓN, R. (1993), «Modernización y cambios en la industria jabonera española (1800-1914)», ponencia presentada en el VII Simposio de Historia Económica. Cambio tecnológico y desarrollo económico, volumen correspondiente a las sesiones III y IV.

RAMÓN, R. (1994), «Los Rocamora, la industria jabonera barcelonesa y el mercado colonial antillano (1845-1913)», Revista de Historia Industrial, núm. 5.

RoCA, J. (1992), «Modernització agrícola i desenvolupament industrial. El cas de Mallorca (1850-1950)», Estudis Baleàrics, núm. 43.

RULE, J. (1990), Clase obrera e industrialización. Historia social de revolución industrial británica, 1750-1850, Crítica (Barcelona).

RosSelló Verger, V. M. (1982), «Canvis de propietat i parcel-lacions al camp mallorquí entre els segles XIX i XX», Randa, núm. 12.

SATORRAS, F. (1883), Memoria sobre el estado de la agricultura en esta provincia, Archivo de la Delegación del Ministerio de Agricultura, Palma.

SATORRAS, F. (1887), Memoria sobre el estado de la agricultura en la provincia de Baleares, Archivo de la Delegación del Ministerio de Agricultura, Palma.

SATORRAs, F. (1901), Abonos minerales. Instrucción para su aplicación en Mallorca, Tipografía de B. Rotger (Palma).

SEgurA, A., y SUAU, J. (1981), «Aproximació a l'estudi de la pagesia mallorquina al primer terç del segle XIX», Bolletí de la Societat Arqueològica Lul-liana, núm. 835.

SUAU, J. (1991), El món rural mallorqui, segles XVIII-XIX, Curial (Barcelona).

TEDDE, P. (1974), «La banca privada española durante la Restauración (1874-1914)», en AUTORES DIVERSOS, La banca española en la Restauración, Servicio de Estudios del Banco de España (Madrid). 
TORTella, G. (1994), El desarrollo de la España contemporánea. Historia económica de los siglos XIX y XX, Alianza Universidad (Madrid).

URECH, C. (1869), Estudios sobre la riqueza territorial de las Islas Baleares dedicados a las Cortes Constituyentes, Imprenta Felipe Guasp (Palma).

VAQUER, B. (1986), La electrificación de Mallorca, Gas y Electricidad, S. A. (Palma).

VIDAL, A. (1991), «Les activitats industrials a Llucmajor (1870-1936). De les farineres a la importència del calçat», en C. MANERA y J. M. Petrus (coord.), Del taller a la fábrica. El procés d'industrialització a Mallorca, Ajuntament de Palma (Palma).

WrIGLEY, E. A. (1989), «Dos tipos de capitalismo, dos tipos de crecimiento», Estudis d'Història Econòmica (1989-1).

Wrigley, E. A. (1992), Gentes, ciudades y riqueza. La transformación de la sociedad tradicional, Crítica (Barcelona).

Wrugley, E. A. (1993), Cambio, continuidad y azar. Carácter de la Revolución Industrial inglesa, Crítica (Barcelona). 